\title{
壳聚糖负载铜催化剂在有机反应中的应用研究进展
}

\author{
张瑶瑶*,a周丽洁 $a, b$ 韩彪 $a, b$ 李维双 $a$ \\ 李博解 $*, a$ 朱 䂞 $*, a, b, c$

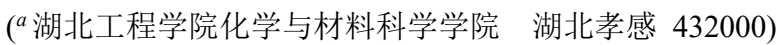 \\ ( $b$ 湖北大学材料科学与工程学院 武汉 430062) \\ ( $c$ 华中科技大学生物无机化学与药物湖北省重点实验室 武汉 430074)
}

\begin{abstract}
摘要 壳聚糖是由甲壳素脱乙酰化而得, 是一种丰富可再生的生物质资源. 壳聚糖分子结构中含有大量的羟基、氨基, 与金属纳米粒子或金属离子具有较强的鳌合能力, 被广泛用作载体制备异相催化剂. 近年来, 壳聚糖负载铜催化剂被 成功应用于各种不同类型的有机反应中，不仅具有反应活性高、选择性好、易于分离回收等优点，而且能够多次循环 再利用，在降低反应成本的同时，也提升了实际的工业应用价值. 因此，从不同类型壳聚糖负载铜催化剂的制备出发， 综述其催化的各种类型的有机反应，主要涉及 $\mathrm{C}-\mathrm{C}$ 键和 $\mathrm{C}-\mathrm{X}$ 键的构建、点击化学及氧化还原反应等类型，促进今后 壳聚糖及其衍生物负载催化剂更加广泛的应用.
\end{abstract}

关键词＼cjkstart壳聚糖负载铜催化剂; 有机反应; 异相催化; 绿色化学; 循环再利用

\section{Research Progress of Chitosan Supported Copper Catalyst in Organic Reactions}

\author{
Zhang, Yaoyao*,a \\ Zhou, Lijie ${ }^{a, b}$ \\ Han, Biao ${ }^{a, b}$ \\ Li, Weishuang ${ }^{a}$ \\ $\mathrm{Li}, \mathrm{Bojie}{ }^{*, a}$ \\ Zhu, Lei ${ }^{*, a, b, c}$ \\ $\left({ }^{a}\right.$ School of Chemistry and Materials Science, Hubei Engineering University, Xiaogan, Hubei 432000) \\ ( ${ }^{b}$ School of Materials Science and Engineering, Hubei University, Wuhan 430062) \\ ( ${ }^{c}$ Hubei Key Laboratory of Bioinorganic Chemistry \& Materia Medica, Huazhong University of \\ Science and Technology, Wuhan 430074)
}

\begin{abstract}
Chitosan is obtained by deacetylation of chitin and is a kind of abundant renewable biomass resource. The molecular structure of chitosan contains a large number of hydroxyl and amino groups, which have strong bonding ability with metal nanoparticles or metal ions. Thus it has been widely used to support various metal particles for the preparation of catalysts. In recent years, chitosan supported copper catalyst has been successfully applied in various types of organic reactions. It has the advantages of high reactivity, good selectivity, easy separation, and can also be reused for many times, which reduces the reaction cost and improves the actual industrial application value. Therefore, based on the preparation of different types of chitosan supported copper catalysts, various types of organic reactions are reviewed, mainly involving the constructions of $\mathrm{C}-\mathrm{C}$ bond and $\mathrm{C}-\mathrm{X}$ bond, click chemistry and oxidation/reduction reactions. It will promote the application of chitosan and its derivatives-supported catalysts in the future.

Keywords chitosan supported copper catalyst; organic reaction; heterogeneous catalysis; green chemistry; recycle and reuse
\end{abstract}

随着能源和环境保护问题的日益突出，高效且可有 效重复使用催化剂的制备及应用显得尤为重要. 均相催
化剂在反应过程中没有传质问题，催化效率高、选择性 好、反应条件温和，但往往难以回收. 利用载体负载金

\footnotetext{
* Corresponding authors. E-mail: yaoyaozhang@hbeu.edu.cn; boji.li@hbeu.edu.cn; lei.zhu@hbeu.edu.cn

Received July 31, 2021; revised September 11, 2021; published online September 26, 2021.

Project supported by the National Natural Science Foundation of China (Nos. 21774029, 22108065), the Natural Science Foundation of Hubei Province (No. 2019CFB354), the Young and Middle-Aged Science and Technology Innovation Team Project in Higher Education Institutions of Hubei Province (No. T201816), and the Natural Science Foundation of Xiaogan City (Nos. XGKJ2020010053, XGKJ2021010009).

国家自然科学基金(Nos. 21774029, 22108065)、湖北省自然科学基金(No. 2019CFB354)、湖北省高等学校优秀中青年科技创新团队计划(No. T201816)、 孝感市自然科学计划(Nos. XGKJ2020010053, XGKJ2021010009)资助项目.
} 
属纳米粒子或金属离子制备为催化剂，通过异相催化的 方式催化反应，在保持高反应活性的同时，可实现催化 剂的回收利用.

壳聚糖(Chitosan, CS)作为一种廉价低毒、来源广泛 的天然高分子, 具有优良的生物相容性和可降解性, 近 年来被广泛应用于医药、农业、日化等众多领域 ${ }^{[1-8]}$. 壳 聚糖分子结构中含有大量的差基和氨基(图 1), 能够通 过多种化学反应修饰制备不同类型的壳聚糖衍生物, 如 羧甲基化 ${ }^{[9]}$ 、磺化 ${ }^{[10]}$ 、卤化 ${ }^{[11]}$ 和酰胺化反应 ${ }^{[12-14]}$ 等, 尤 其是可与醛反应生成席夫碱, 增强其配位能力. 壳聚糖 及其衍生物能够有效络合各种类型的金属粒子 $(\mathrm{Au} 、 \mathrm{Ag}$ 、

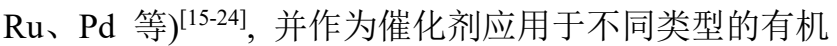
反应中 ${ }^{[25]}$. 与单一壳聚糖相比, 修饰后的壳聚糖衍生物 作为载体时, 所得催化剂可能表现出不同的催化活性或 选择性, 从而进一步扩大了壳聚糖载体的应用范围.

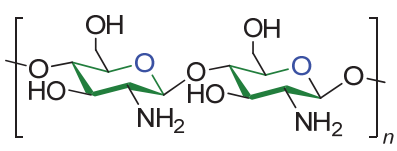

图 1 壳聚糖分子结构

Figure 1 The structure of chitosan (CS)

目前，壳聚糖负载金属催化剂的制备方法主要有: 利用壳聚糖直接吸附金属离子得到催化剂; 或将各种醛 类化合物与壳聚糖上的氨基进行缩合反应得到含 Schiff 碱结构的壳聚糖配体，再与金属盐络合制备得到催化剂 等. 壳聚糖负载催化剂通常是以异相催化的形式参与有 机反应, 在反应结束后可简便地从体系中分离, 并且回 收再利用, 更加满足绿色化学的需求. 该类催化剂具有 制备方法简单、活性高、可循环使用、适用范围广、物 理化学性质稳定、可在水相中高效反应等优点.

另一方面, 与贵金属相比, 铜具有来源广泛、价格 低廉等优点, 因此以壳聚糖为载体, 负载金属铜粒子制 备的催化剂, 不仅可有效抑制铜的流失, 拓展催化反应 的类型和适用范围, 而且可实现催化剂的回收再利用. 本论文针对近年来壳聚糖负载铜催化剂在不同类型有 机反应中的应用进行综述，具体以 $\mathrm{C}-\mathrm{C}$ 键、 $\mathrm{C}-\mathrm{X}$ 键、 点击反应、氧化还原反应为分类, 从壳聚糖载体化学修 饰和功能化设计、催化剂性能及回收利用等内容进行详 细的归纳和总结.

\section{1 壳聚糖负载铜在构建 C-C 键中的应用}

$\mathrm{C}-\mathrm{C}$ 键是构成有机化合物基本骨架的重要化学键, 因此构建 $\mathrm{C}-\mathrm{C}$ 键是有机合成中最核心的研究内容之 一. 过渡金属催化的有机反应是构建 $\mathrm{C}-\mathrm{C}$ 键的重要工 具, 例如 Grignard 反应、Heck 反应、Suzuki 反应等. 随
着社会环境保护意识的增强，以绿色环保的方法构建 $\mathrm{C}-\mathrm{C}$ 键逐渐引起化学家们的广泛关注 ${ }^{[26-27]}$. 近年来, 以壳聚糖负载铜作为催化剂应用于各种类型 $\mathrm{C}-\mathrm{C}$ 键构 建被陆续报道.

2002 年，夏春谷课题组 ${ }^{[28]}$ 利用水杨醛衍生物对壳 聚糖进行改性，以得到的壳聚糖-席夫碱配合物作为载 体, 吸附 $\mathrm{Cu}(\mathrm{II})$ 后制备出催化剂 $\mathbf{C 1} \sim \mathbf{C 4}$. 红外光谱(IR) 和 $\mathrm{X}$ 射线光电子能谱(XPS)测试结果表明，铜离子成功 地与催化剂中席夫碱结构进行配位. 作者比较了 $\mathbf{C 1}$ C4 在催化苯乙烯环丙烷化反应中的催化性能，发现四 种催化剂均表现出较高的催化活性(89\% 92\%), 其中, C1 产率最高( $92 \%), \mathbf{C 3}$ 对映选择性最高 $(23 \% e e)$, 说明 水杨醛苯环上的取代基对反应结果有显著影响(Scheme 1). 与之相比，在相同条件下，利用未修饰的单一壳聚 糖直接吸附 $\mathrm{Cu}(\mathrm{II})$ 作为催化剂时，该反应无法进行，说 明席夫碱的结构修饰对于催化剂的活性起到关键作用, 可显著增强壳聚糖载体与铜离子的络合作用. 此外, 该 体系中催化剂可在反应结束后通过简单的过滤操作实 现回收利用，循环五次后依然保持较高的催化活性. 在
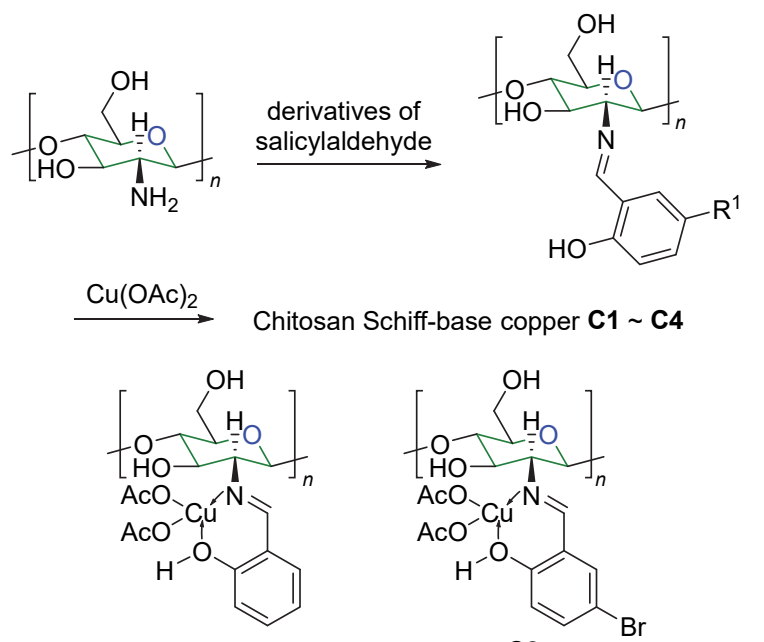

C1

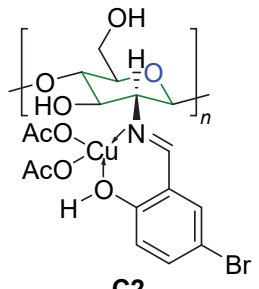

C2
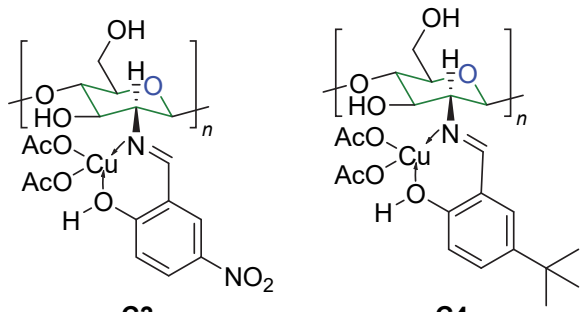

C3

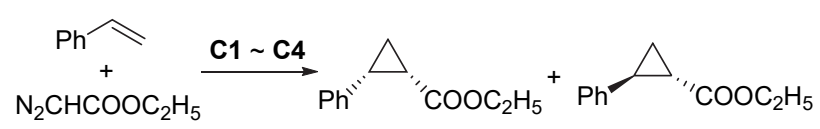

图式 1 壳聚糖-席夫碱铜 $(\mathbf{C 1} \sim \mathbf{C 4})$ 催化烯烃的环丙烷化反应 Scheme 1 Cyclopropanation of styrene by chitosan-Schiff base copper catalysts $(\mathbf{C 1} \sim \mathbf{C 4})$ 
该反应中, 重氮化合物起始原料首先与催化剂形成活性 铜卡宾中间体, 之后再与烯烃发生不对称环丙烷化反 应，进而得到具有对映选择性的目标产物。

2013 年, 张先满课题组 ${ }^{[29]}$ 开发了一种简单新颖的 方法来制备多孔壳聚糖微球(PCMS)负载 $\mathrm{CuI}$ 催化剂 (PCMS@CuI, C5), 可用于各种碘代芳烃的 Heck 交叉偶 联反应(Scheme 2). 与已有文献报道的均相铜催化体系 相比，该方法反应速率更快，底物范围更广，但是该反 应需要在高温下进行, 且需要额外添加 KOAc 作为碱. 本工作的机理研究表明, PCMS@CuI 催化剂活性中心为 $\mathrm{Cu}(\mathrm{I})$, 而非碘离子或多孔壳聚糖微球. 催化剂中的多孔 壳聚糖微球不仅是优良的负载基质, 也是一种良好的配 体，其结构中的官能团可有效螯合 $\mathrm{Cu}(\mathrm{I})$.
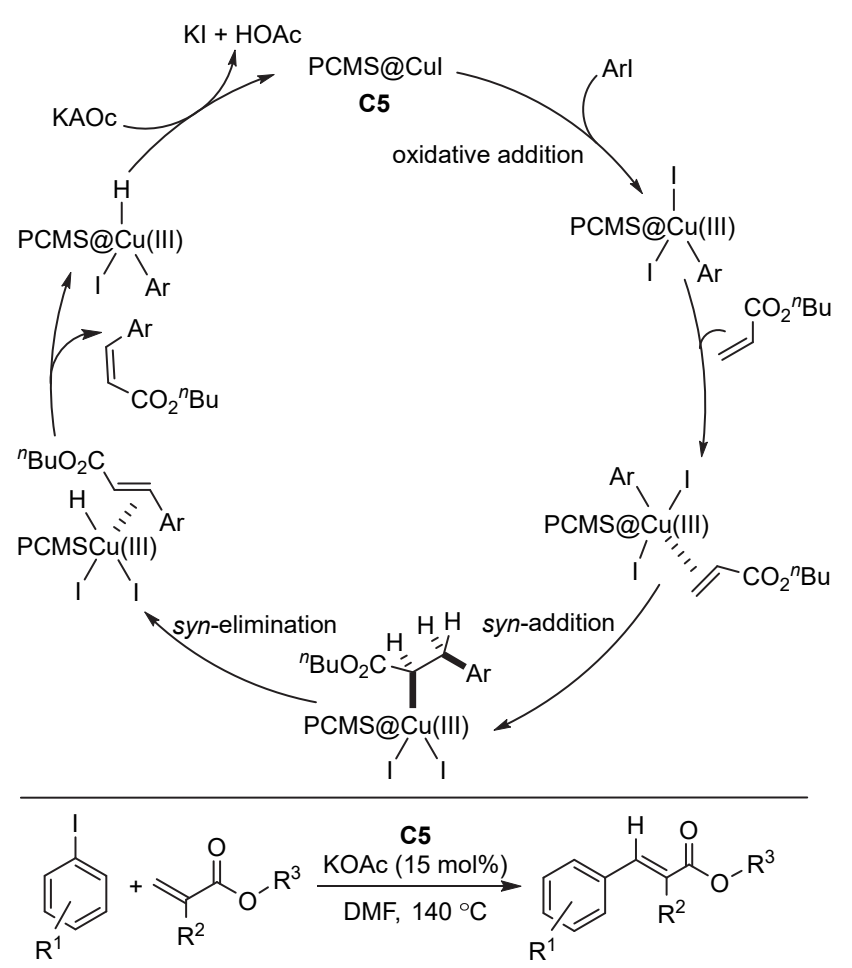

$\mathrm{R}^{1}=4-\mathrm{CH}_{3}, 4-\mathrm{F}, 2-\mathrm{CH}_{3} \mathrm{O}, 4-\mathrm{Br}, 3-\mathrm{CH}_{3} \mathrm{O}, 3-\mathrm{Cl}, 2-\mathrm{Cl}, 3-\mathrm{F}, 2-\mathrm{CH}_{3}, \mathrm{H}$ $\mathrm{R}^{2}=\mathrm{CH}_{3}, \mathrm{H}$ $\mathrm{R}^{3}={ }^{n} \mathrm{Bu}, \mathrm{CH}_{3}$

图式 2 PCMS@CuI (C5)催化 Heck 反应可能机理 Scheme 2 Proposed mechanism of PCMS@CuI (C5) catalyzed Heck reaction

2015 年, 徐建鸿课题组 ${ }^{[30]}$ 采用简便的微流控方法, 制备了一种具有优异机械性能和吸附性能的二氧化硅/ 壳聚糖杂化微球负载 $\mathrm{CuI}$ 催化剂. 该催化剂具有独特的 核一壳结构, 在无溶剂的末端炔烃偶联反应中表现出优 异的催化活性(产率 $>90 \%$ ). 与均相催化体系相比, 该 催化剂可有效降低传质阻力, 从而显著提高催化活性. 同时, 二氧化硅/壳聚糖杂化微球可以吸附末端炔烃, 进 而促使催化剂周围的反应物浓度提高, 加快催化反应速
率. 该催化剂在最优条件下(铜含量为 $2.2 \mathrm{~mol} \%$ ), 室温 时 $10 \mathrm{~min}$ 内即可完成反应，产率达到 $96 \%$. 该负载型催 化剂稳定性好、催化性能高, 可循环使用五次以上且不 丧失催化活性，整个反应及回收过程绿色环保.

2016 年, 章鹏飞课题组 ${ }^{[31]}$ 通过简单的吸附沉积制 备得到壳聚糖负载铜异相催化剂 $\mathrm{CS} @ \mathrm{Cu}(\mathrm{OAc})_{2}(\mathbf{C} \boldsymbol{6})$, 利用成本低、稳定性良好的 Langlois 试剂 $\left(\mathrm{CF}_{3} \mathrm{SO}_{2} \mathrm{Na}\right)$ 作为 “ $\mathrm{CF}_{3}$ ” 源 ${ }^{[32]}$, 在温和条件下成功实现了 8-苯甲酰 氨基喹啉衍生物的三氟甲基化反应(Scheme 3), 通过选 择性活化 $\mathrm{C}-\mathrm{H}$ 键, 获得相应的偶联产物, 且转化效率 高(62\% 92\%), 官能团耐受性好. 该催化剂在保持良 好收率的情况下，同时容易回收使用，为异相铜催化剂 在选择性 $\mathrm{C}-\mathrm{H}$ 键活化中的有效再利用研究提供了新途 径. 该反应在自由基抑制剂(TEMPO)存在的条件下被完 全抑制，证实反应过程中有自由基的参与. 根据对照实 验的结果, 作者提出可能的机理为: 首先催化剂 CS@$\mathrm{Cu}(\mathrm{OAc})_{2}$ 与喹啉衍生物形成络合物, 三氟甲基自由基 通过单电子转移的方式进攻喹啉衍生物的 5-位, $\mathrm{Cu}(\mathrm{II})$ 被还原为 $\mathrm{Cu}(\mathrm{I})$, 之后 $\mathrm{K}_{2} \mathrm{~S}_{2} \mathrm{O}_{8}$ 将 $\mathrm{Cu}(\mathrm{I})$ 氧化, 经质子转移 后生成最终目标产物, 同时实现催化剂的再生. 此外, 通过类似的自由基光电催化过程, 实现了喹噁啉与烯 烃 ${ }^{[33]}$ 和芳香胺 ${ }^{[34]}$ 的 $\mathrm{C}-\mathrm{C}$ 偶联反应, 相较于金属催化过 程中需要的高温条件 ${ }^{[35]}$, 该类方法在室温下即可完成 高效的转化.

2016 年, Dekamin 课题组 ${ }^{[36]}$ 采用壳聚糖溶液吸附 $\mathrm{CuSO}_{4} \cdot 5 \mathrm{H}_{2} \mathrm{O}$ 得到催化剂 $\mathbf{C}$, 并应用于催化合成 1,4-二 氢吡啶(DHP)和多氢喹啉(PHQ)衍生物(Scheme 4). 作者 通过电感耦合等离子体原子发射光谱法(ICP-AES)表征, 得到催化剂中铜离子含量为 $5.1 \mathrm{~mol} \%$, 并根据此测试结 果, 考察出最优催化剂用量为 $20 \mathrm{mg}$. 在此用量下, 将 该催化剂应用于醛、酯和醋酸铵三组分反应中, 实现了 在低铜负载量下的一锅法转变, 得到良好至优异的目标 产物收率，且催化剂可有效重复使用.

2017 年, Pathak 课题组 ${ }^{[37]}$ 利用壳聚糖和 8-羟基喹 啉-2-甲醛进行缩合反应得到壳聚糖一席夫碱配体, 再吸 附 $\mathrm{Cu}(\mathrm{OAc})_{2} \cdot \mathrm{H}_{2} \mathrm{O}$ 后合成出一种新型的壳聚糖负载的席 夫碱 $\mathrm{Cu}(\mathrm{II})$ 配合物(C8). 作者利用 IR、紫外-可见分光光 度法(UV-Vis)、X 射线衍射(XRD)、XPS 等多种测试手 段对催化剂 $\mathbf{C 8}$ 的席夫碱络合结构进行了表征, 并且证 明回收后催化剂结构依旧保持完整. 该催化剂在末端炔 烃的氧化偶联反应中表现出较高的催化活性(Scheme $5)$, 产率中等到良好 $(63 \% \sim 91 \%), \mathrm{TON}$ 为 118 . 另外，该 小组评估了催化剂的重复使用性能, 发现循环五次催化 活性没有明显降低. 

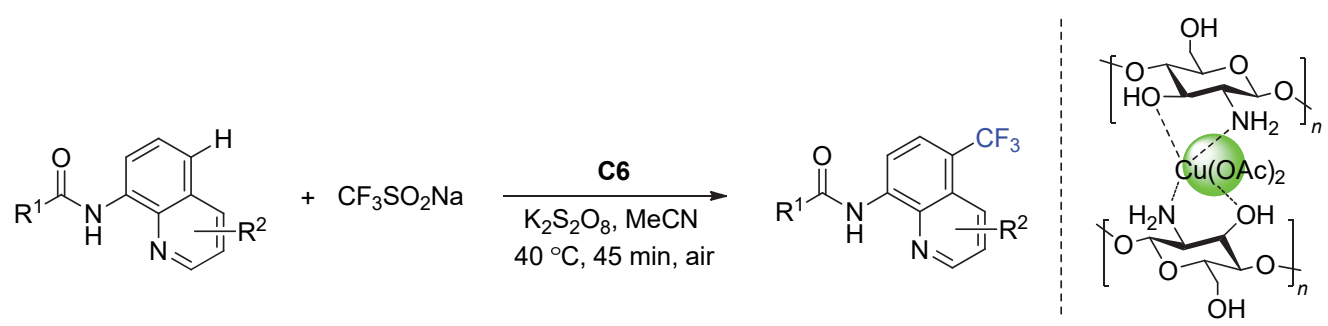<smiles>[R]c1ccc(C(=O)Nc2ccc(C(F)(F)F)c3cccnc23)cc1</smiles>

$\mathrm{R}^{\prime}=\mathrm{H}, 89 \% ; \mathrm{R}^{\prime}=\mathrm{Me}, 90 \%$ $\mathrm{R}^{\prime}=\mathrm{OMe}, 92 \% ; \mathrm{R}^{\prime}=\mathrm{Br}, 85 \%$<smiles>CC(=O)Nc1ccc(C(F)(F)F)c2cccnc12</smiles>

$85 \%$<smiles>O=C(Nc1ccc(C(F)(F)F)c2cccnc12)C1CCCO1</smiles><smiles>[R7]c1ccccc1C(=O)Nc1ccc(C(F)(F)F)c2cccnc12</smiles>

$\mathrm{R}^{\prime \prime}=\mathrm{Me}, 88 \% ; \mathrm{R}^{\prime \prime}=\mathrm{F}, 83 \%$ $\mathrm{R}^{\prime \prime}=\mathrm{Ph}, 81 \% ; \mathrm{R}^{\prime \prime}=\mathrm{CF}_{3}, 76 \%$<smiles>O=C(Nc1ccc(C(F)(F)F)c2cccnc12)C1CC1</smiles>
$88 \%$<smiles>O=C(Nc1ccc(C(F)(F)F)c2cccnc12)c1cccs1</smiles>
$62 \%$<smiles>Cc1cccc(C(=O)Nc2ccc(C(F)(F)F)c3cccnc23)c1</smiles>

$91 \%$<smiles>O=C(Nc1ccc(C(F)(F)F)c2cccnc12)C1CCCCC1</smiles>
$91 \%$<smiles>O=C(Nc1ccc(C(F)(F)F)c2cccnc12)c1ccccc1</smiles><smiles>O=C(Nc1ccc(C(F)(F)F)c2cccnc12)c1ccc(Cl)cc1Cl</smiles><smiles>COCC(=O)Nc1ccc(C(F)(F)F)c2cccnc12</smiles>

图式 $3 \quad \mathrm{CS} @ \mathrm{Cu}(\mathrm{OAc})_{2}(\mathbf{C 6})$ 催化的 8-氨基喹啉酰胺的三氟甲基化反应 Scheme 3 Trifluoromethylation of 8-aminoquinoline amides catalyzed by $\mathrm{CS} @ \mathrm{Cu}(\mathrm{OAc})_{2}(\mathbf{C 6})$<smiles>[R]OC(=O)C1=C(C)NC(C)C(C(=O)O[R])=C1c1ccc([R7])cc1</smiles>

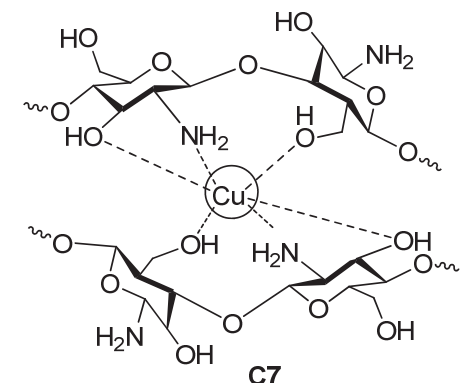<smiles>CCOC(=O)C1=C(C)NC(C)C(C(=O)OCC)=C1c1ccc(Cl)cc1</smiles><smiles>CCOC(=O)C1=C(C)NC(C)C(C(=O)OCC)=C1c1ccc(F)cc1</smiles><smiles>CCOC(=O)C1=C(C)NC(C)C(c2ccc([N+](=O)[O-])cc2)=C1C(=O)OCC</smiles><smiles>CCOC(=O)C1=C(C)NC(C)C(C(=O)OCC)=C1c1ccc(Br)cc1</smiles>
$95 \%$<smiles>CCOC(=O)C1=C(C)NC(C)C(C(=O)OCC)=C1c1ccccc1</smiles>

$93 \%$

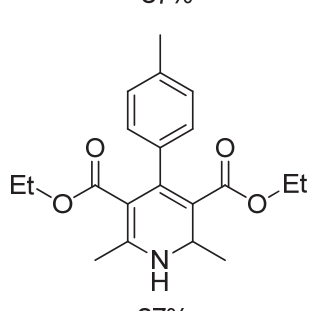

图式 $4 \mathbf{C} 7$ 催化不同醛和 $\beta$-二羰基化合物合成不同的 1,4-DHP 衍生物

Scheme 4 C7 catalyzed synthesis of different 1,4-DHP derivatives from different aldehydes and $\beta$-dicarbonyl compounds 

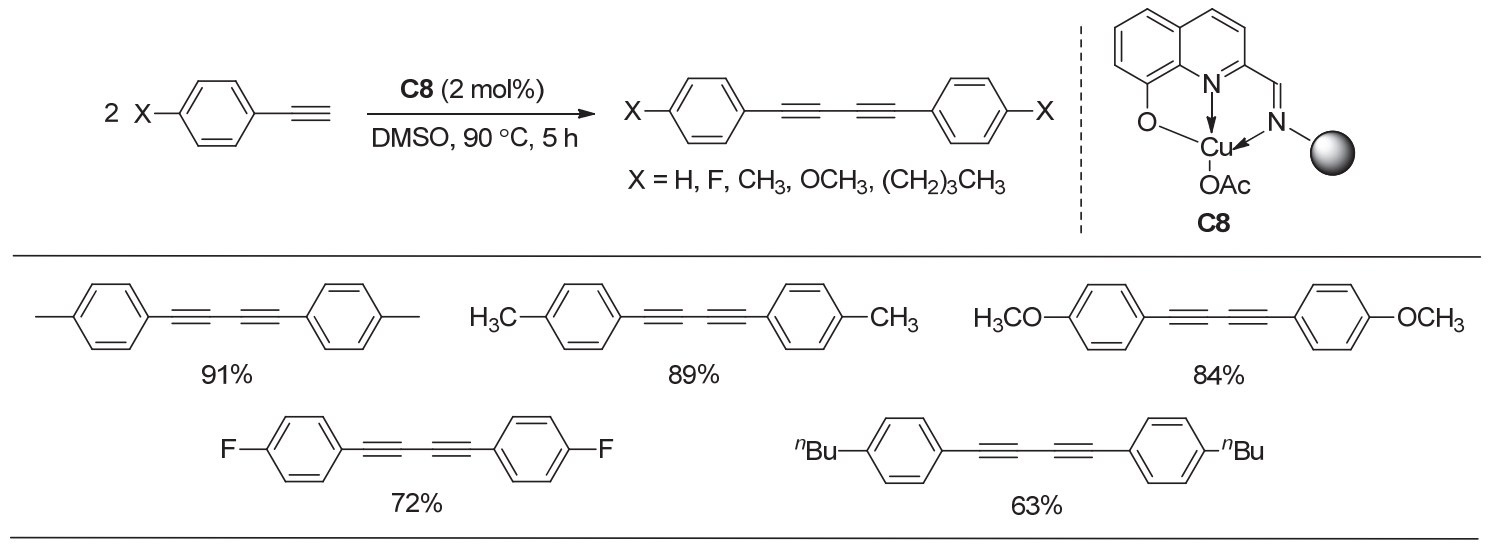

图式 5 催化剂 $\mathbf{C 8}$ 的结构及末端炔烃氧化偶联

Scheme 5 Structure of $\mathbf{C 8}$ and oxidative homo-coupling of terminal alkynes

2018 年, Gil 课题组 ${ }^{[38]}$ 报道了两种络合 $\mathrm{Cu}(\mathrm{OAc})_{2}$ 的 吡啶改性壳聚糖衍生物催化剂的制备方法, 作者首先将 2-吡啶甲醛和 6-甲基-2-吡啶甲醛分别成功接枝到壳聚 糖骨架上, 随后络合 $\mathrm{Cu}(\mathrm{OAc})_{2}$ 得到催化剂 C9 和 $\mathbf{C 1 0}$, 如 Scheme 6 所示. 为了研究 C9 和 C10 的催化性能, 将 其分别应用于苯甲醛转化为 1-苯基-2-硝基乙醇的反应, 产率分别为 $96 \%$ 和 $95 \%$, 实现了壳聚糖负载铜催化的异 相 Henry 反应(Scheme 6).

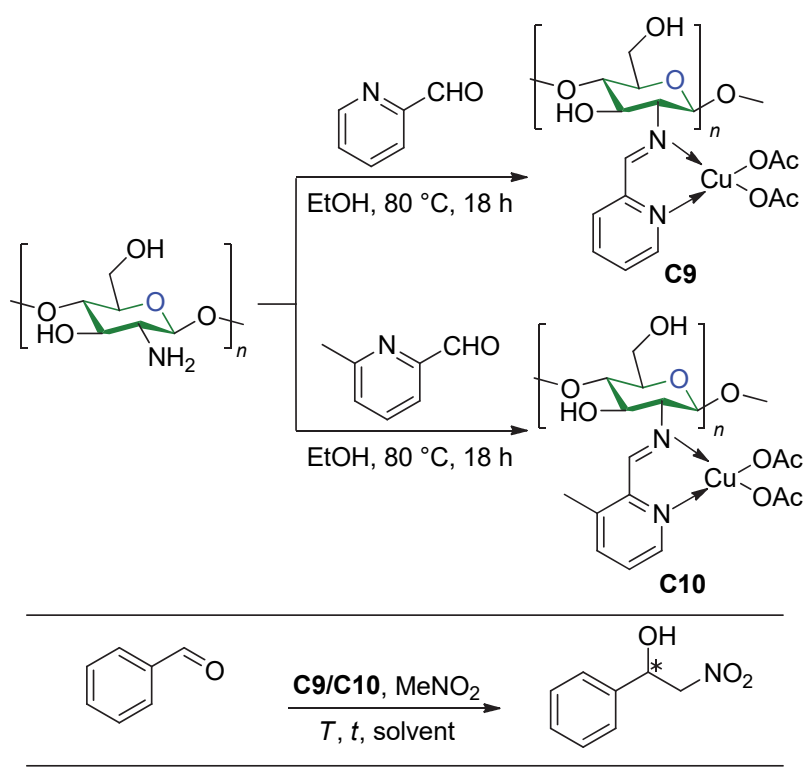

图式 6 壳聚糖衍生物 C9 和 C10 合成路线及 Henry 反应 Scheme 6 Synthesis route of chitosan derivatives C9 and C10 and catalyzed for Henry (nitroaldol) reaction

2018 年, Kumar 课题组 ${ }^{[39]}$ 制备了一种壳聚糖负载 $\mathrm{CuI}$ 催化剂 CS@CuI (C11), 并采用扫描电子显微镜-元 素分析仪(SEM-EDS)观察到铜离子均匀地分布在壳聚 糖载体表面. 作者将该催化剂在 $140{ }^{\circ} \mathrm{C} 、 \mathrm{~N}_{2}$ 气氛及无溶 剂的条件下，应用于醛、胺、炔的三组分偶联反应 $\left(\mathrm{A}^{3}\right.$
偶联反应)，成功得到不同取代的丙炔胺化合物(Scheme 7). 底物拓展结果表明，该催化体系可适用于不同类型 的环状仲胺, 如吗啉、哌啶、 $N$-甲基/苯基哌嗪等, 而伯 胺则无法反应. 在最优化条件下，作者循环使用催化剂 C11 六次, 该 $\mathrm{A}^{3}$ 偶联反应均能得到优异的收率. 此外, 回收后的催化剂经电感耦合等离子体质谱(ICP-MS)测

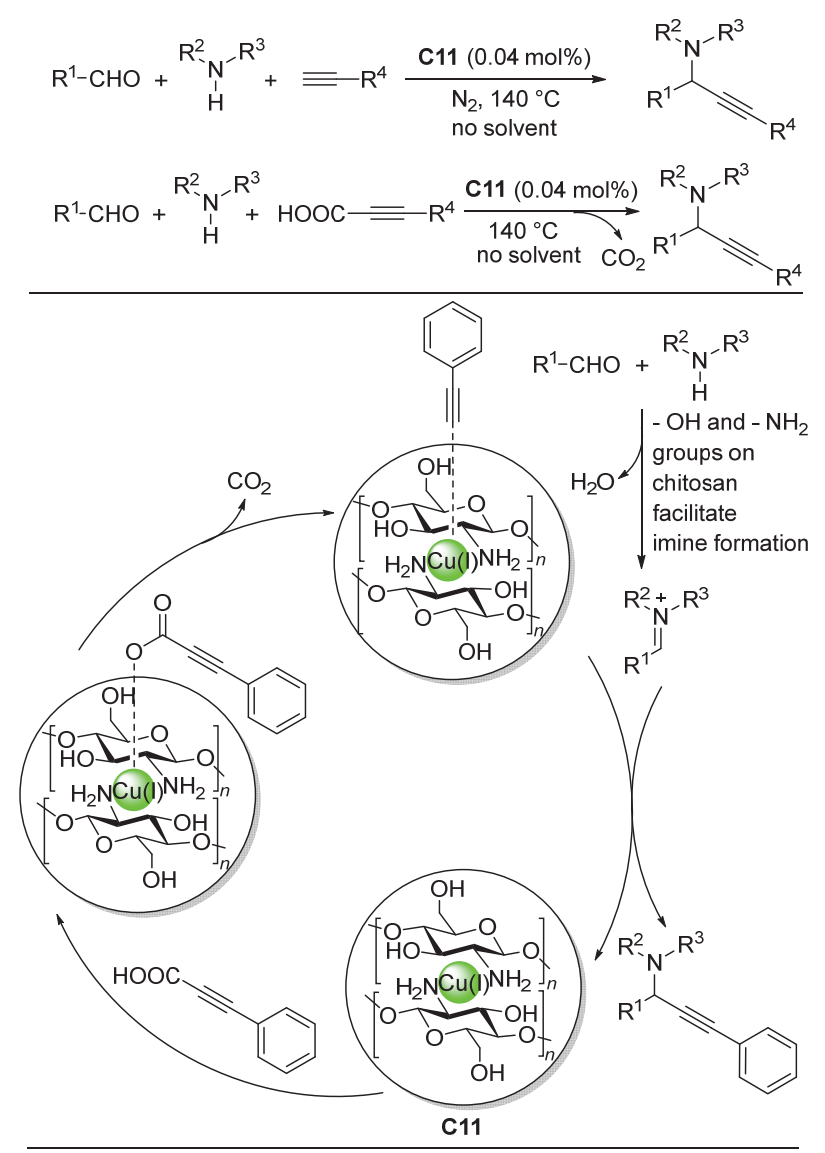

图式 $7 \mathrm{CS} @ \mathrm{CuI}(\mathbf{C 1 1})$ 催化 $\mathrm{A}^{3}$ /脱羧 $\mathrm{A}^{3}$ 偶联反应及可能机理 Scheme 7 CS@CuI (C11) catalyzed $\mathrm{A}^{3} /$ decarboxylative $\mathrm{A}^{3}$ coupling reaction and proposed reaction mechanism 
试，表明在反应前后催化剂中铜含量基本不变，反应过 程中无明显铜离子浸出. 这一实验及表征结果证实了壳 聚糖与金属离子的结合相对牢固, 能最大程度减少金属 浸出, 从而实现催化剂的有效回收利用.

2018 年, 曾敏峰课题组 ${ }^{[40]}$ 在酸性介质中, 将壳聚糖 氨基质子化后形成阳离子大分子, 再通过离子交换进行 蒙脱土插层, 最后将 $\mathrm{Pd}^{0}$ 和 $\mathrm{Cu}^{2+}$ 分别与 $\mathrm{NH}_{2}$ 和 $\mathrm{OH}$ 络合, 得到一种高效的异相蒙脱土/壳聚糖复合双金属催化剂 (MMT/CS@ $\mathrm{Pd}^{0} / \mathrm{Cu}^{2+}, \mathrm{C12}$ ). 该催化剂中的 $\mathrm{Pd}^{0}$ 和 $\mathrm{Cu}^{2+}$ 含量经 ICP-AES 测试分别为 0.016 和 $0.014 \mathrm{mmol} / \mathrm{g}$. 高 分辨透射电镜(HR-TEM)表征证明, 纳米离子 $\mathrm{Pd}^{0} / \mathrm{Cu}^{2+}$ 成功固定在多孔复合材料的孔道结构中, 表现为均匀的 颗粒状. 将该催化剂应用于水/醚混合溶剂中催化 Sonagashira 偶联反应时, 表现出优异的催化性能 (Scheme 8). 但是, 当催化剂循环使用至第 6 次时, 产率 下降至 $70 \%$, 其可能原因是, 在回收过程中, 铜离子流 失从而导致催化剂活性下降.

从以上壳聚糖负载铜催化剂应用于 $\mathrm{C}-\mathrm{C}$ 键构建的 实例可知, 壳聚糖及其衍生物通过简单负载铜即可得到
具有高效催化活性的催化剂, 在应用于各种 $\mathrm{C}-\mathrm{C}$ 偶联 反应中时，表现出高催化性能、易于回收等特性，所制 备得到的催化剂均为异相催化剂, 形貌多样, 具有微球 结构和孔状结构等.

\section{2 壳聚糖负载铜在构建 C-X 键中的应用}

碳杂键是有机分子中常见的化学键, 构建 $\mathrm{C}-\mathrm{X}$ 键 是十分重要的研究方向, 迄今为止, 许多药物多为杂环 化合物，含 $\mathrm{N} 、 \mathrm{O} 、 \mathrm{~S}$ 等杂原子. 碳杂键通常是通过芳基 卤化物和杂原子亲核试剂，在过渡金属催化剂的作用下 发生偶联反应来制备，因此，壳聚糖负载铜催化剂在 $\mathrm{C}-\mathrm{X}$ 键构建中的应用具有重要的理论和现实意义 ${ }^{[41]}$.

\section{$2.1 \mathrm{C}-\mathrm{N}$ 键的构建}

2015 年, Pramanik 课题组 ${ }^{[42]}$ 建立了一种简单易行的 合成 $N$-芳基脂肪族化合物的方法(Scheme 9). 作者利用 壳聚糖吸附 $\mathrm{CuSO}_{4}$ 制备出催化剂 $\mathbf{C 1 3}$ ，并将其用于卤代 芳烃和脂肪胺的反应中. 实验结果表明, 催化剂 C13 应 用于该反应时，在较短时间内即可得到非常高的产率，

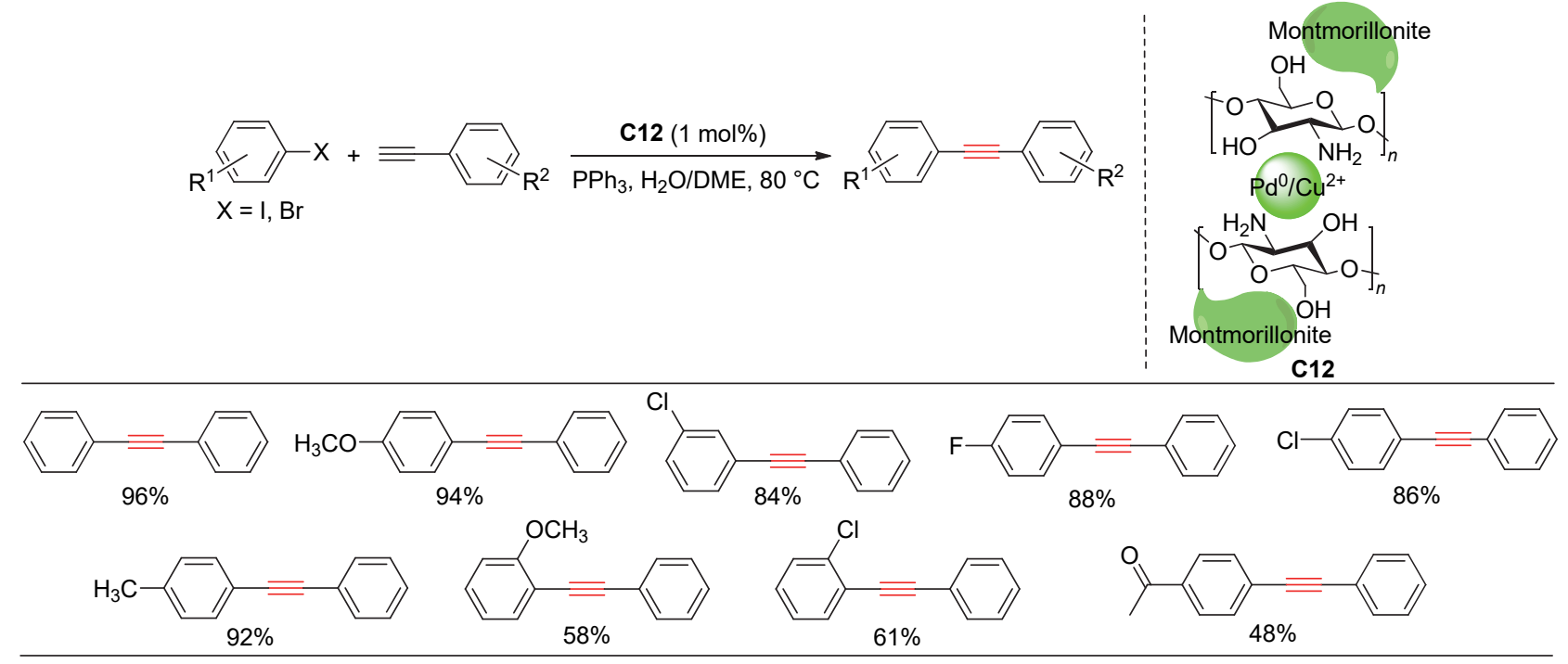

图式 $8 \mathrm{MMT} / \mathrm{CS} @ \mathrm{Pd}^{0} / \mathrm{Cu}^{2+}(\mathbf{C 1 2})$ 催化芳族卤化物与炔烃的 Sonogashira 交叉偶联反应

Scheme 8 MMT/CS@ $\mathrm{Pd}^{0} / \mathrm{Cu}^{2+}(\mathbf{C 1 2})$ catalyzed Sonogashira cross-coupling of aromatic halides with alkynes
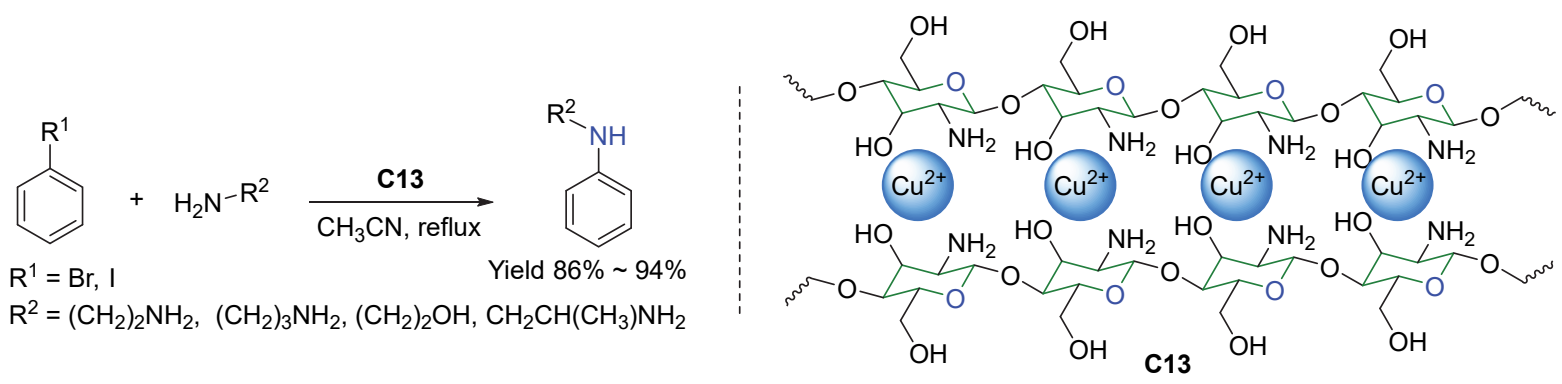

图式 9 二胺与氨基醇的偶联反应

Scheme $9 \mathrm{C}-\mathrm{N}$ cross coupling between aryl halides and aliphatic diamines 
同时简化了操作步骤. 该催化剂经过简单过滤回收再利 用，循环使用五次后，产率从 $94 \%$ 下降到 $84 \%$ ，反应性 能有所下降.

2015 年, Pathak 课题组 ${ }^{[43]}$ 报道了一种壳聚糖席夫碱 配合物负载 $\mathrm{Cu}(\mathrm{II})$ 的合成方法. 首先利用水杨醛修饰壳 聚糖, 再与邻羟基芳香亚胺、 $\mathrm{Cu}(\mathrm{OAc})_{2}$ 在乙醇中回流 $12 \sim 15 \mathrm{~h}$ 得到壳聚糖-席夫碱配合物负载铜催化剂 (C14 C16). 将该催化剂应用于 Chan-Lam 偶联反应中 (Scheme 10), 催化剂 C16 效果最好, 可能是由于硝基的 吸电子效应，增强了配合物的路易斯酸性，从而提高了
反应活性．该方法也可进一步拓展到各种不同类型芳香 胺或脂肪胺与苯硼酸的反应，均取得不错的收率。反应 完成后，通过过滤可以将催化剂有效分离，并且能够重 复使用四次以上.

2015 年，朱新海课题组 ${ }^{[44]}$ 利用席夫碱反应对壳聚 糖结构进行修饰，再利用 $\mathrm{NaBH}_{4}$ 还原亚胺键，得到壳聚 糖基多齿配体 C17，并将其应用于纯水相中的 Ullman 偶联反应构建 C- $\mathrm{N}$ 键(Scheme 11). 实验结果表明各种 芳香胺的 Ullmann 偶联均能顺利进行, 并以较高的收率 得到目标产物，底物范围包括茮基胺、脂肪族胺和咪唑
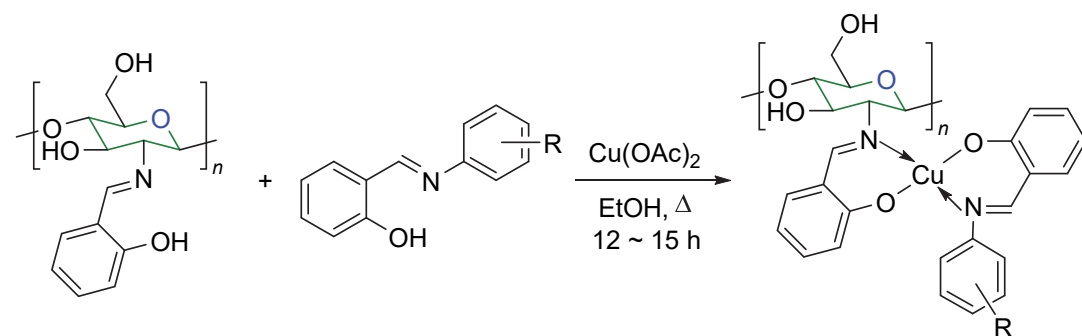

$\mathrm{C} 14, \mathrm{R}=\mathrm{H}$

$\mathrm{C} 15, \mathrm{R}=p-\mathrm{OCH}_{3}$

$\mathrm{C} 16, \mathrm{R}=m-\mathrm{NO}_{2}$
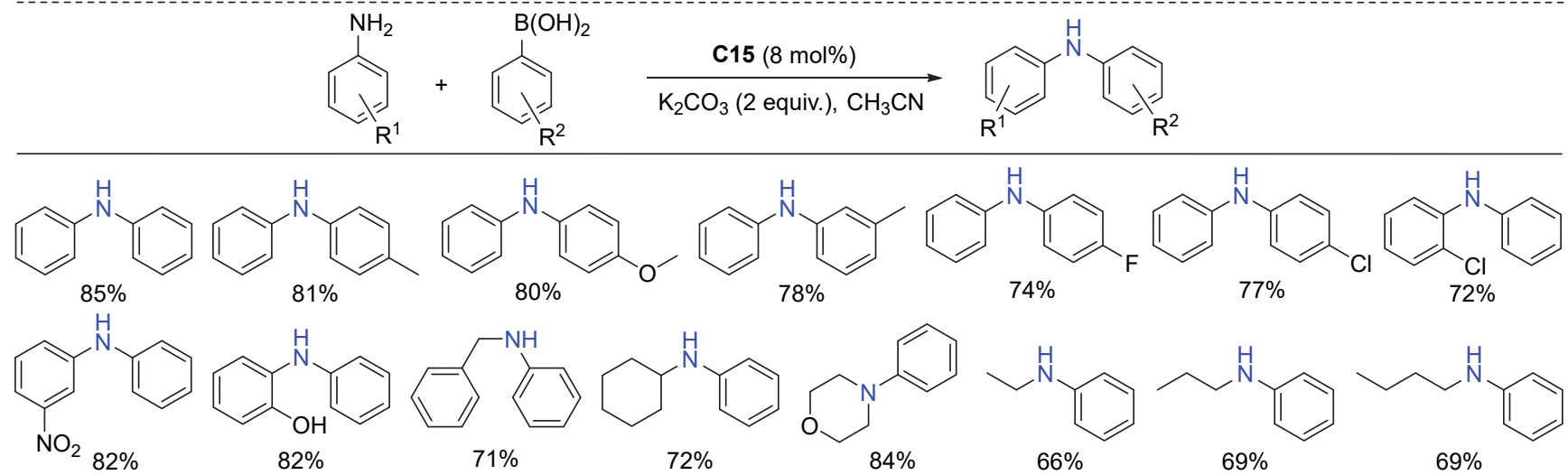<smiles>CCNc1ccccc1</smiles><smiles>CCCNc1ccccc1</smiles>

$69 \%$

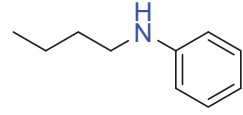

图式 10 壳聚糖针定铜席夫碱(C14 C16)的制备及催化胺的 $N$-芳基化

Scheme 10 Preparation of chitosan anchored copper(II) Schiff base complexes $(\mathbf{C 1 3} \sim \mathbf{C 1 5})$ and catalyzed $N$-arylation of amines
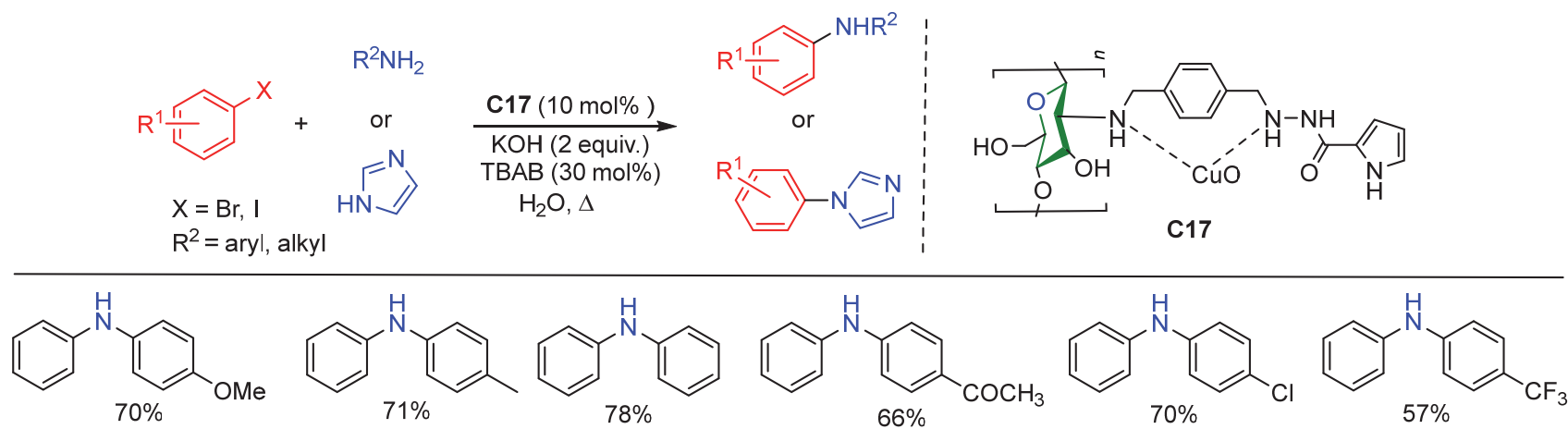<smiles>O=[N+]([O-])c1ccc(Nc2ccccc2)cc1</smiles><smiles>COc1ccccc1Nc1ccccc1</smiles>

$84 \%$<smiles>COc1cccc(Nc2ccccc2)c1</smiles>

$74 \%$<smiles>Clc1cccc(Nc2ccccc2)c1</smiles>

$87 \%$<smiles>Cc1cc(C)cc(Nc2ccccc2)c1</smiles><smiles>O=[W]OC(=O)c1ccsc1Nc1ccccc1</smiles>

图式 11 催化剂 CSP@CuO 的结构及其催化卤代芳烃与苯胺偶联反应

Scheme 11 Coupling reactions of aryl halides with aniline and structure of CSP@CuO 
等. 本工作的优势在于, 采用水为反应溶剂, 配体可简 单过滤实现重复使用, 该工作实现了催化剂的绿色化及 经济化

2018 年, 葛新课题组 ${ }^{[45]}$ 分别利用 2-吡啶甲醛、水杨 醛、2-吡啶甲酸对壳聚糖进行修饰, 吸附 $\mathrm{CuI}$ 制备催化 剂 $\mathbf{C 1 8}$ C20. 实验优化结果表明, 在咪唑与碘苯的 Ullmann 偶联反应中, 催化剂 C18 效果最佳, 证实修饰 单元的结构对于吸附 $\mathrm{Cu}(\mathrm{I})$ 的效果和催化剂的活性有显 著影响. 在最优化条件下, 各类碘取代芳族化合物均能 够顺利地与咪唑、环己胺等发生偶联反应, 表现出优良 的底物适应性(Scheme 12). 反应结束后, 经过过滤、洗 涤将催化剂进行分离，可有效重复使用五次.
2020 年, Nasrollahzadeh 课题组 ${ }^{[46]}$ 使用大戟叶提取 物作为还原剂, 制备出一种环保经济的磁性壳聚糖一铜 纳米复合材料 $\mathrm{Fe}_{3} \mathrm{O}_{4} \mathrm{NPs} @ \mathrm{Cu}^{0}$ (C21) (Scheme 13). 场发 射扫描电子显微镜(FESEM)、透射电子显微镜(TEM)、 XRD、EDS 表征证明，该催化剂结构完整, TEM 显示铜 纳米粒子催化剂平均粒径为 $5 \sim 10 \mathrm{~nm}$, 壳聚糖呈现球 形。该催化剂在各种四氮唑化合物的合成中表现出很好 的催化效果，且反应条件温和、成本低廉. 值得一提的 是, 由于催化剂中含有磁性四氧化三铁, 故通过简单磁 性分离, 即可实现催化剂的有效回收及重复使用. 2021 年, 该课题组 ${ }^{[47]} 又$ 进一步将壳聚糖结构进行改性, 制备 出离子液体功能化壳聚糖铜催化剂 $\mathbf{C 2 2}$, 实现了四氮唑

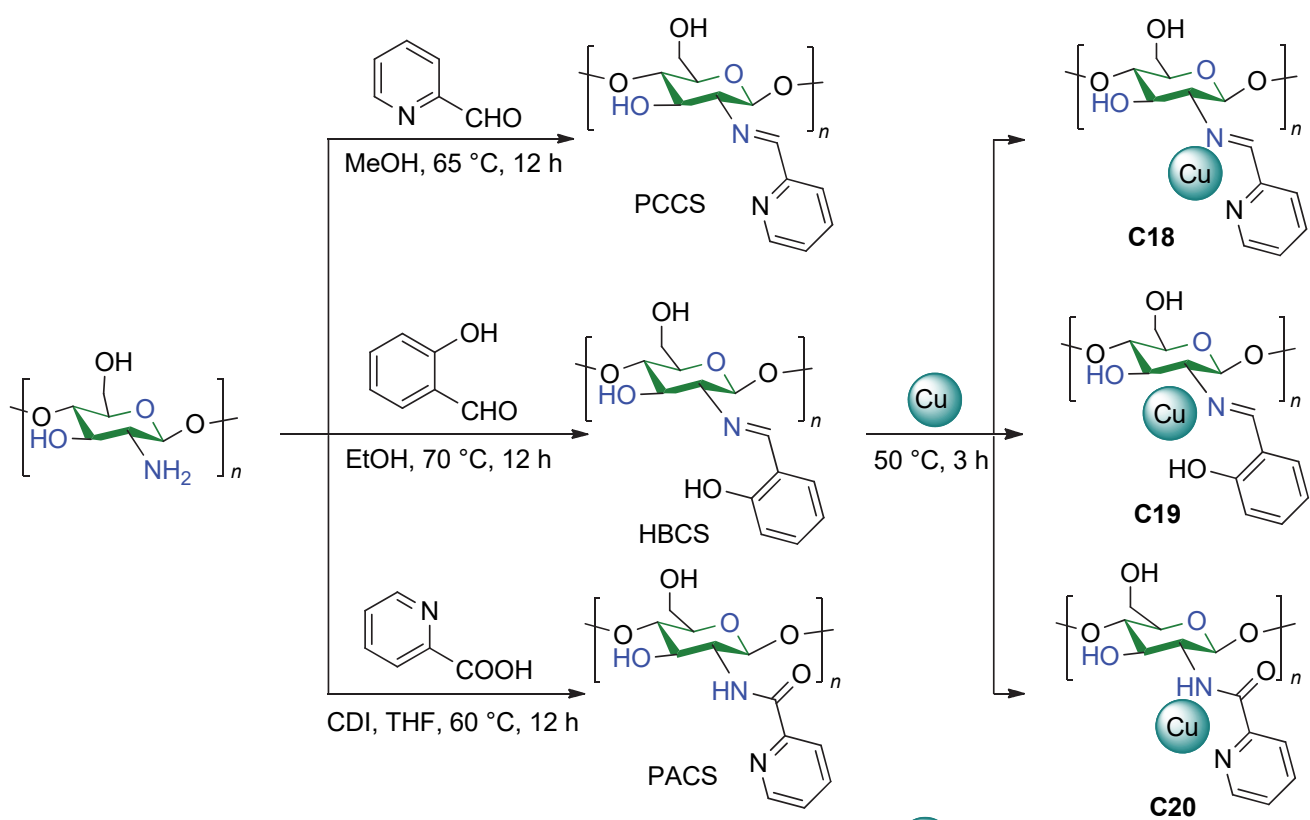

$\mathrm{Cu}=\mathrm{Cul}, \mathrm{CuSO}_{4}, \mathrm{Cu}(\mathrm{OAc})_{2}$

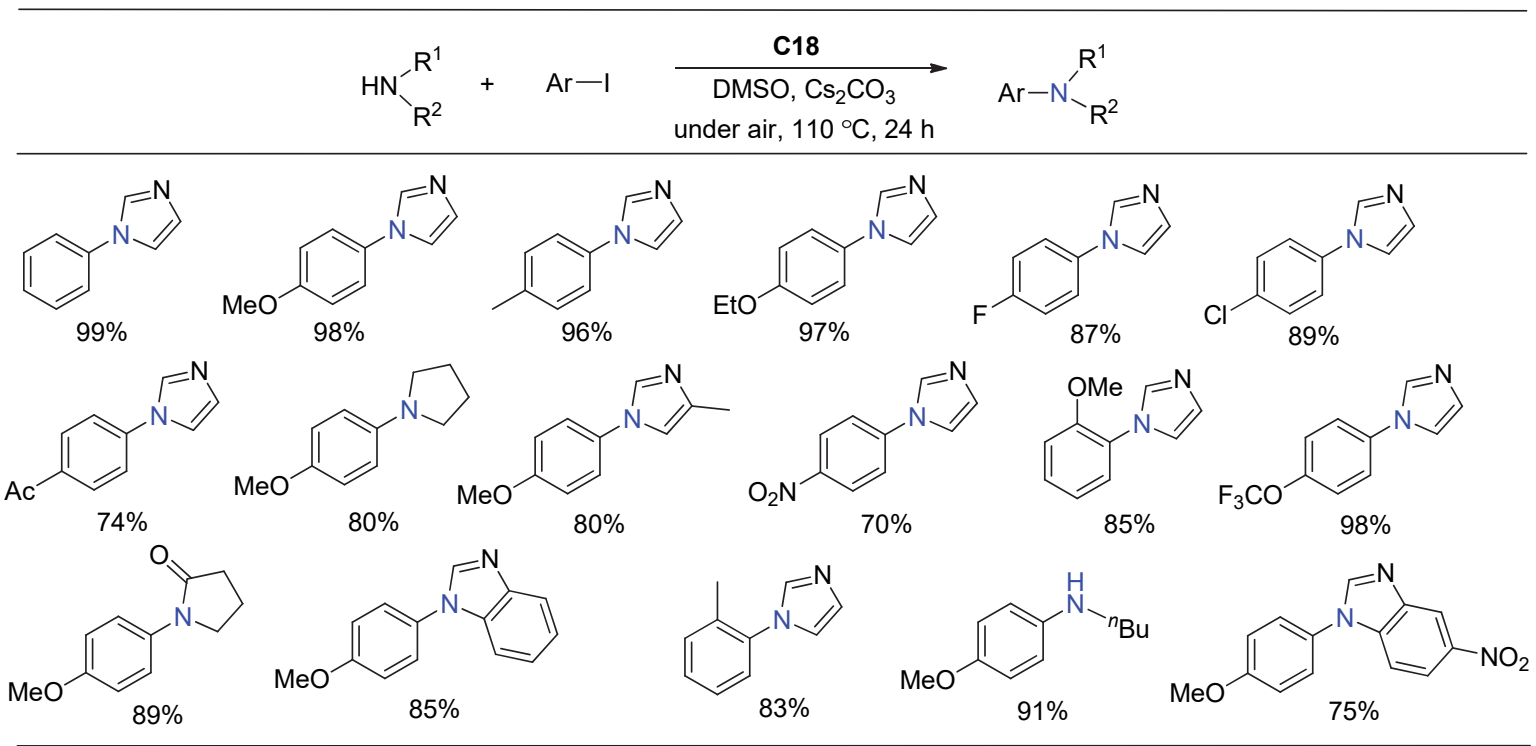

图式 12 PCCS@CuI (C18)催化的 C-N 偶联反应

Scheme 12 PCCS@CuI $(\mathbf{C 1 8})$ catalyzed C-N coupling reaction 


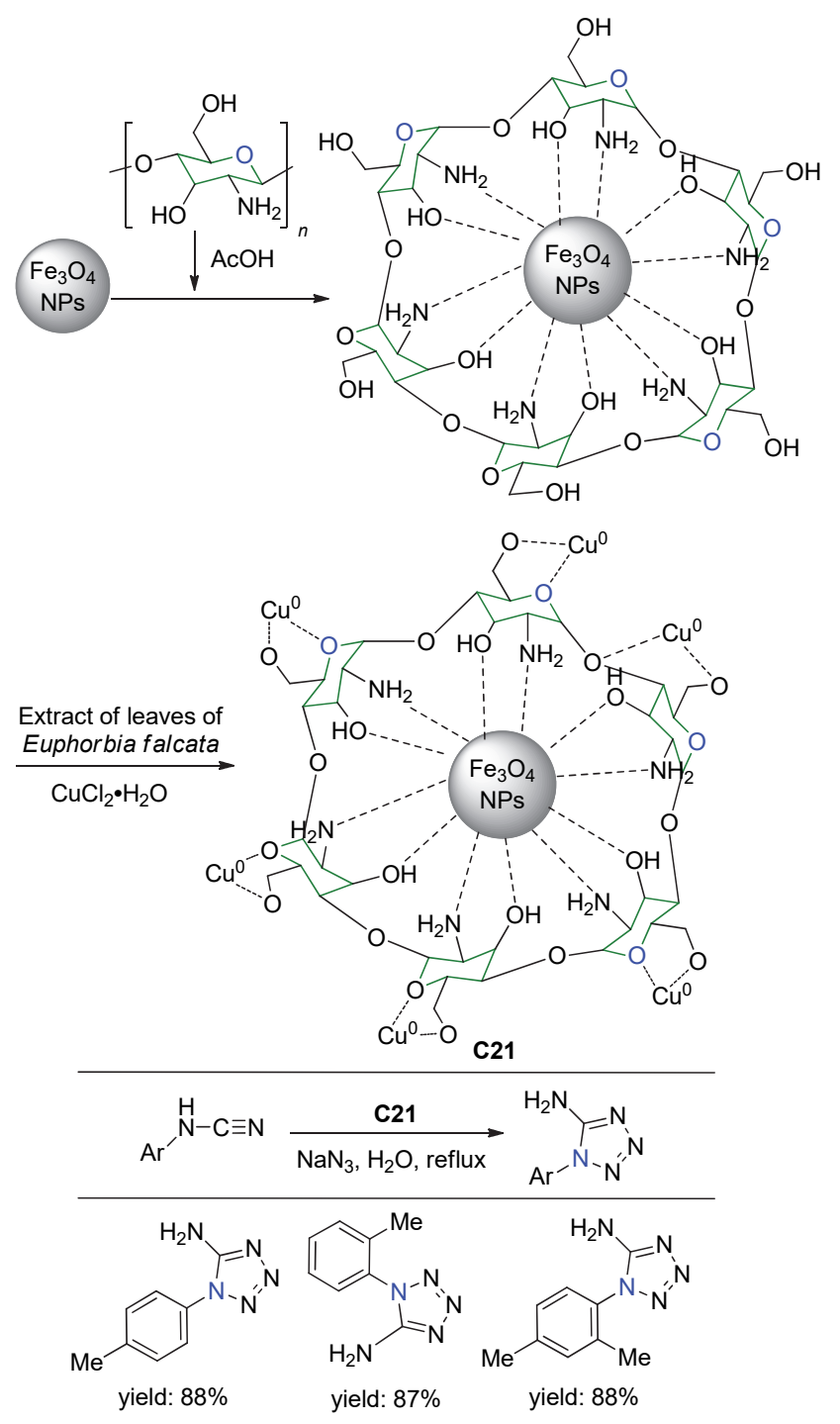

图式 13 催化剂 $\mathbf{C 2 1}$ 的制备及催化 $\mathrm{C}-\mathrm{N}$ 偶联反应

Scheme 13 Preparation of $\mathbf{C 2 1}$ and catalyzed $\mathrm{C}-\mathrm{N}$ coupling reaction

化合物的选择性高效合成(Scheme 14).

\section{$2.2 \mathrm{C}-\mathrm{S}$ 键的构建}

在有机化合物中, 硫醚是重要的中间体, $\mathrm{C}-\mathrm{S}$ 键具 有很高的反应活性, 传统 $\mathrm{C}-\mathrm{S}$ 键的构建需要比较严苛 的条件, 如高温、强极性溶剂等. 2014 年, 章鹏飞课题 组 ${ }^{\left[{ }^{[8]}\right]}$ 开发了一种简单绿色的壳聚糖负载铜催化剂, 用 于催化卤代芳烃与亚硫酸盐的偶联反应(Scheme 15), 可以高产率制备出相应的产物砜, 且官能团耐受性好. 将单一壳聚糖浸在铜盐溶液中吸附铜, 洗涤干燥后得到 壳聚糖负载铜催化剂 $\mathbf{C 2 3} \sim \mathbf{C 2 5}$, 用于碘苯与苯磺酸钠 的偶联反应. 通过反应条件优化得到最佳反应条件: 以 C25 作为催化剂, $\mathrm{KOAc}$ 为碱, $\mathrm{DMSO} / \mathrm{H}_{2} \mathrm{O}$ 混合液为反应 溶剂, $120{ }^{\circ} \mathrm{C}$ 下反应 $24 \mathrm{~h}$, 产率可达 $91 \%$. 在此基础上, 进一步拓展底物范围, 发现具有供电子基团或吸电子基

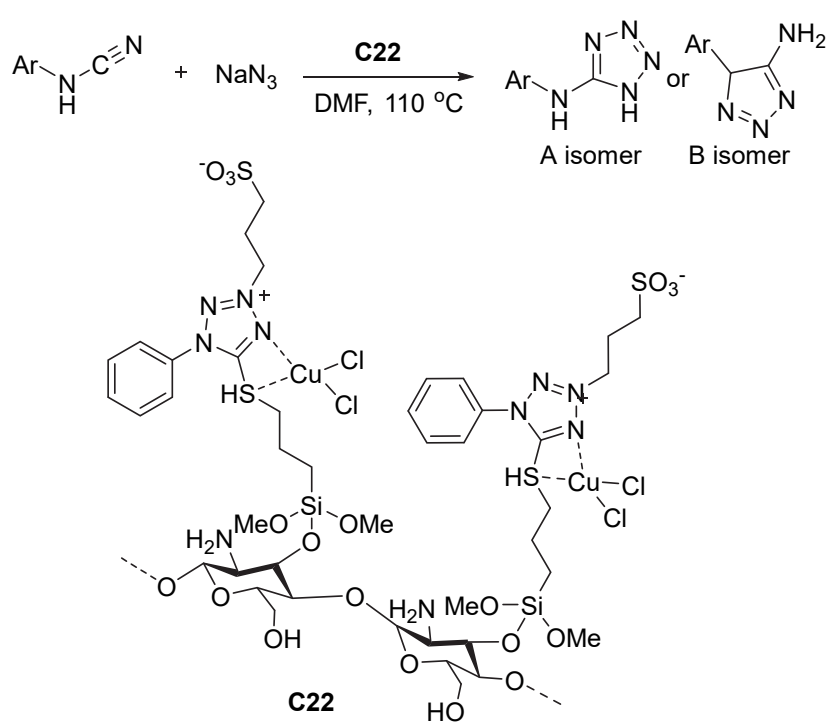

图式 14 CS@Tet-IL-Cu(II) (C22)催化合成芳基胺四氮唑 Scheme 14 Schematic representation of synthesis of arylaminotetrazoles using CS@Tet-IL-Cu(II) (C22)

团的碘代芳烃均能顺利发生反应，且供电子基团的底物 反应产率更高. 催化剂的五次循环利用是通过简单过滤 实现的.

2015 年, Primo 课题组 ${ }^{[49]}$ 在壳聚糖纤维中嵌入铜纳 米粒子作为卤代芳烃与硫酚 $\mathrm{C}-\mathrm{S}$ 偶联反应的多相催化 剂(Scheme 16). 作者采用多元醇还原法将 $\mathrm{Cu}\left(\mathrm{NO}_{3}\right)_{2}$ 还 原成 $\mathrm{Cu}$ 纳米粒子, 将壳聚糖酸性溶液加入上述形成的 $\mathrm{Cu}$ 纳米粒子的乙二醇溶液中得到均匀水凝胶，从而将 $\mathrm{Cu}$ 纳米粒子负载在壳聚糖上, 再向其滴入碱性水溶液, 得到负载 $\mathrm{Cu}$ 的壳聚糖微球, 最后用超临界 $\mathrm{CO}_{2}$ 干燥处 理得到 CS@Cu NPs 催化剂 C26. 将该催化剂用于硫酚 与卤代芳烃的 $\mathrm{C}-\mathrm{S}$ 偶联反应中, 可得到较好的产率 (44\% 99\%), 并且碘代芳烃反应活性要高于溴代芳烃 和氯代芳烃. 进一步研究表明, 过量壳聚糖的存在对催 化活性不利，可能是由于溶液粘度变化过大或对反应试 剂吸附过度而导致. 该催化剂在优化条件下可重复使用 至少四次, 但从第二次使用时催化剂的活性明显降低, 并伴随着少量铜的浸出, 说明壳聚糖载体的结构有待进 一步优化.

2017 年, Hajipour 课题组 ${ }^{[50]}$ 利用组氨酸(his)修饰的 壳聚糖负载 $\mathrm{Cu}(\mathrm{II})$ 纳米粒子作为制备二芳基硫化物和芳 基茮基硫梄的异相催化剂(his/CS@ $\mathrm{Cu}(\mathrm{II}), \mathrm{C} 27$ ). 作者将 此催化剂分别用于一步法三组分 $\mathrm{C}-\mathrm{S}$ 偶联和两组分 $\mathrm{C}-\mathrm{S}$ 偶联反应中, 在最优条件下进行底物拓展. 结果 表明，该催化剂在制备二芳基硫化物和芳基茮基硫醚中 均具有较好的产率, 表现出较高的催化活性(Scheme 17). 通过过滤实现催化剂有效循环使用六次, 且催化 活性也没有明显损失. 虽然该反应需要使用碱作为添加 


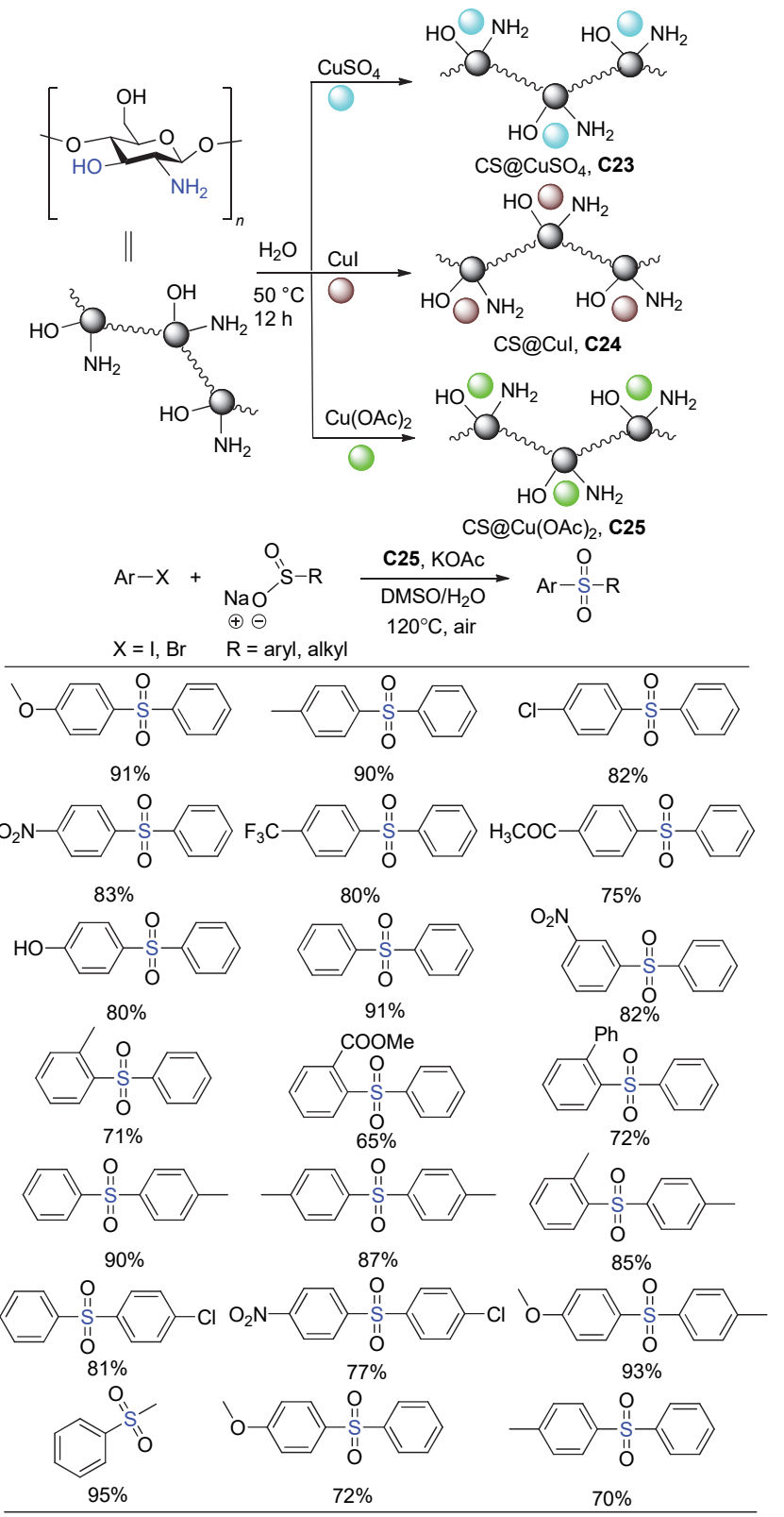

图式 $15 \mathrm{CS} @ \mathrm{Cu}(\mathrm{OAc})_{2}(\mathbf{C 2 5})$ 催化卤代芳烃与亚硫酸钠的 $\mathrm{C}-\mathrm{S}$ 偶联反应

Scheme 15 CS@ $\mathrm{Cu}(\mathrm{OAc})_{2}(\mathbf{C 2 5})$ catalyzed C-S cross-coupling between aryl halides and sodium sulfinates

剂, 但是提供了一种绿色高效的 $\mathrm{C}-\mathrm{S}$ 偶联反应策略.

2020 年, 刘学民课题组 ${ }^{[51]}$ 以 2-吡啶甲酸(PA)改性壳 聚糖作为载体(PACS), 负载铜盐后作为催化剂(PACS$\left(a \mathrm{Cu}(\mathrm{OAc})_{2}, \mathbf{C 2 8}\right)$, 在硫单质为硫源时与吲哚衍生物和 碘苯发生三组分偶联反应, 有效构筑 $\mathrm{C}-\mathrm{S}$ 键 (Scheme 18). 该反应在以 $\mathrm{Cs}_{2} \mathrm{CO}_{3}$ 为碱, $\mathrm{KI}$ 为添加剂, $N, N$-二甲基 甲酰胺(DMF)为溶剂, $110{ }^{\circ} \mathrm{C}$ 下反应效果最佳, 收率可 达 $92 \%$, 且催化剂在最优条件下, 底物适用范围广，易 于分离回收, 并进行有效重复使用.

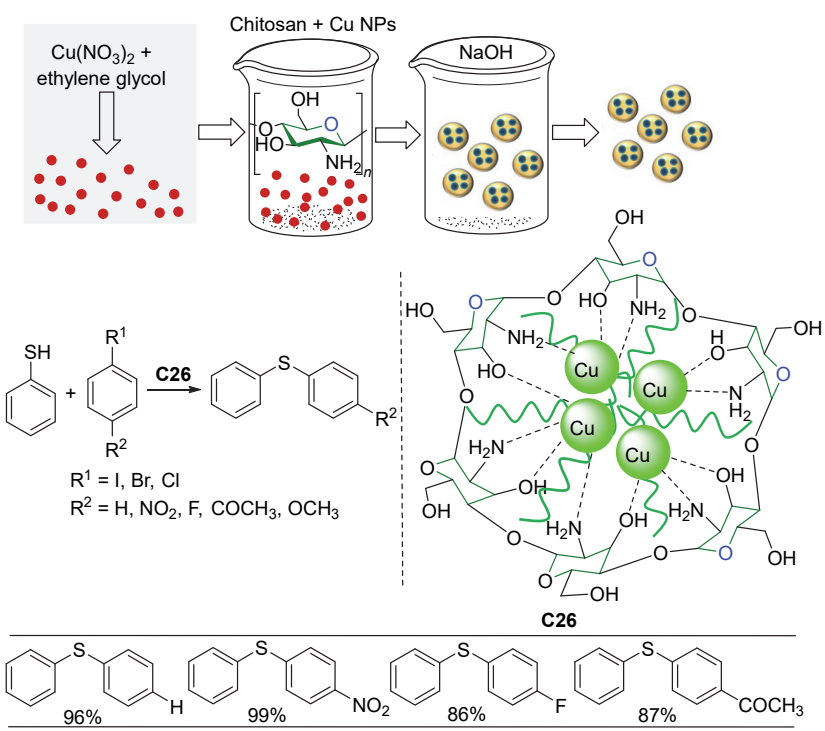

图式 $16 \mathrm{CS} @ \mathrm{Cu}$ NPs $(\mathbf{C 2 6})$ 催化硫酚和芳基卤化物的 $\mathrm{C}-\mathrm{S}$ 偶联反应

Scheme 16 CS@Cu NPs (C26) catalyzed C-S cross-couplings between thiophenol and aryl halides
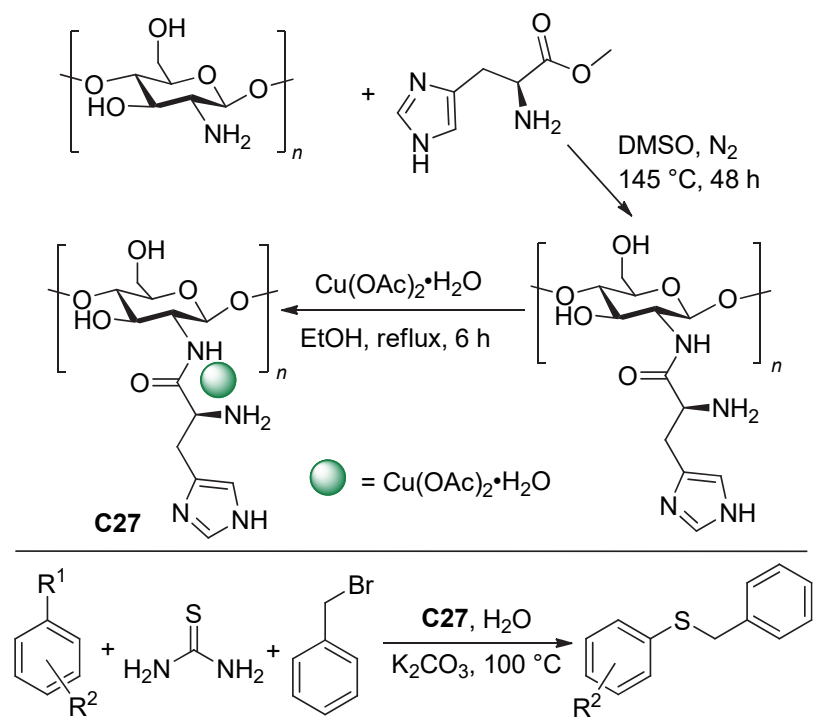

$\mathrm{R}^{1}=\mathrm{Cl}, \mathrm{R}^{2}=\mathrm{H}, 3-\mathrm{CH}_{3}, 4-\mathrm{NO}_{2}, 4-\mathrm{CH}_{3} \mathrm{CO}, 2-\mathrm{CHO}, 2-\mathrm{NO}_{2} \quad 62 \% \sim 80 \%$ $\mathrm{R}^{1}=\mathrm{Br}, \mathrm{R}^{2}=\mathrm{H}, 3-\mathrm{CH}_{3} \mathrm{O}, 4-\mathrm{NO}_{2}, 4-\mathrm{CH}_{3} \mathrm{CO}, 2-\mathrm{CHO}, 2-\mathrm{NO}_{2} 63 \% \sim 86 \%$

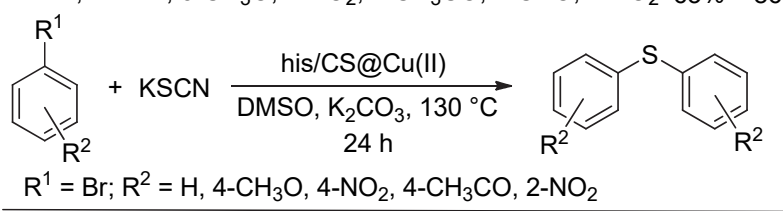

图 17 催化剂 his/CS@ $\mathrm{Cu}(\mathrm{II})(\mathbf{C 2 7})$ 的制备及催化合成芳基苄 基硫醚

Scheme 17 Preparation of his/CS@Cu(II) (C27) and catalyzed to synthesis of aryl benzyl sulfides

\section{$2.3 \mathrm{C}-\mathrm{O}$ 键的构建}

2016 年，章鹏飞课题组 ${ }^{[52]}$ 报道了一例利用壳聚糖 负载铜催化剂构建 $\mathrm{C}-\mathrm{O}$ 键, 用于合成磺酸酯取代喹啉 

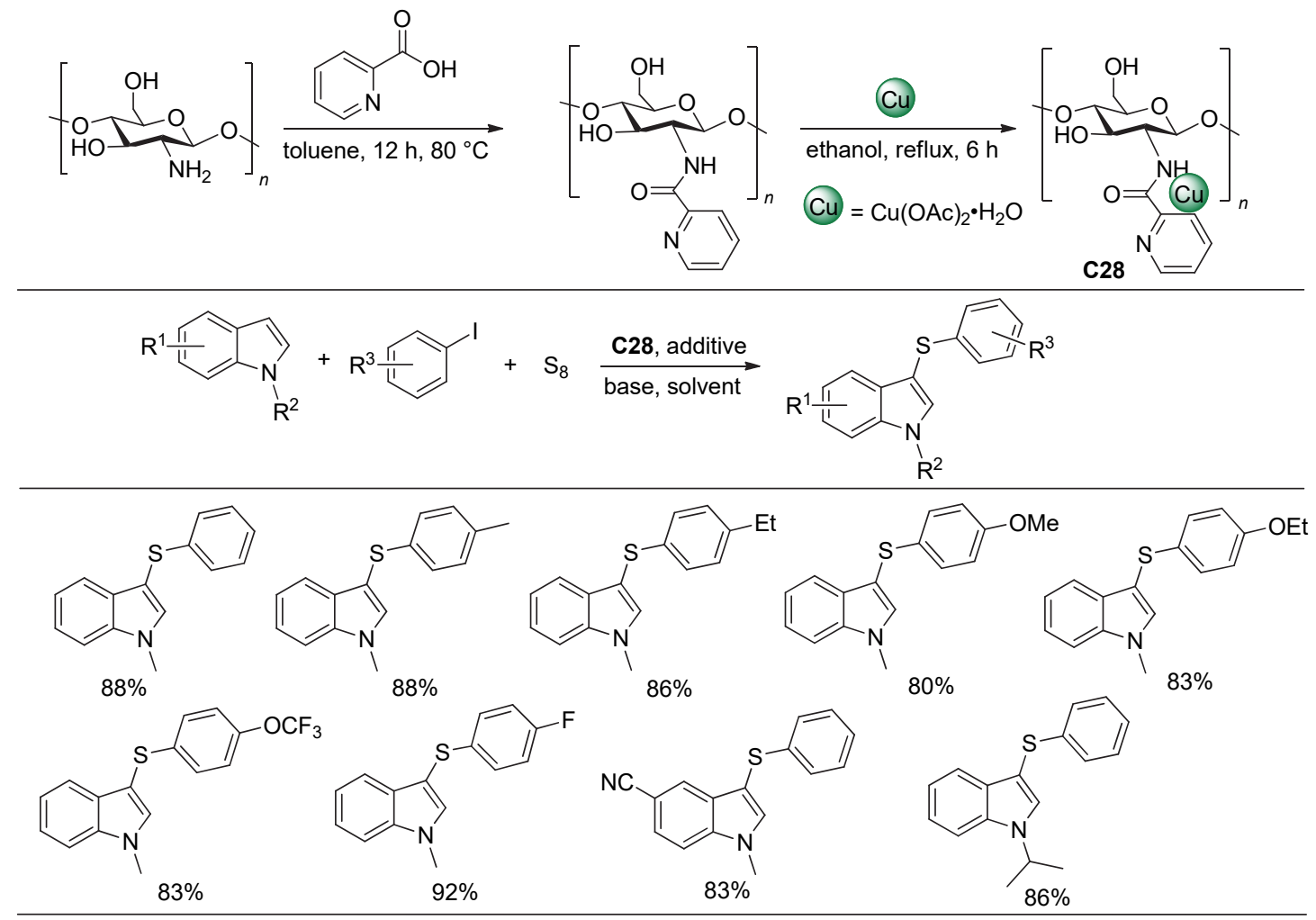

图式 18 催化剂 $\mathbf{C 2 8}$ 的制备路径及其应用于合成芳基苄基硫醚

Scheme 18 Preparation of $\mathbf{C 2 8}$ and application of synthesis aryl benzyl sulfides

类化合物的方法. 作者利用单一壳聚糖吸附 $\mathrm{CuI}$ 作为催 化剂 C29, 以喹啉氮氧化物和对甲基苯磺酰氯为模板底
物，通过条件优化表明以 $\mathrm{K}_{2} \mathrm{CO}_{3}$ 为碱，100 ${ }^{\circ} \mathrm{C}$ 下反应 12 $\mathrm{h}$, 目标产物收率为 $88 \%$ (Scheme 19). 在此最优条件下,

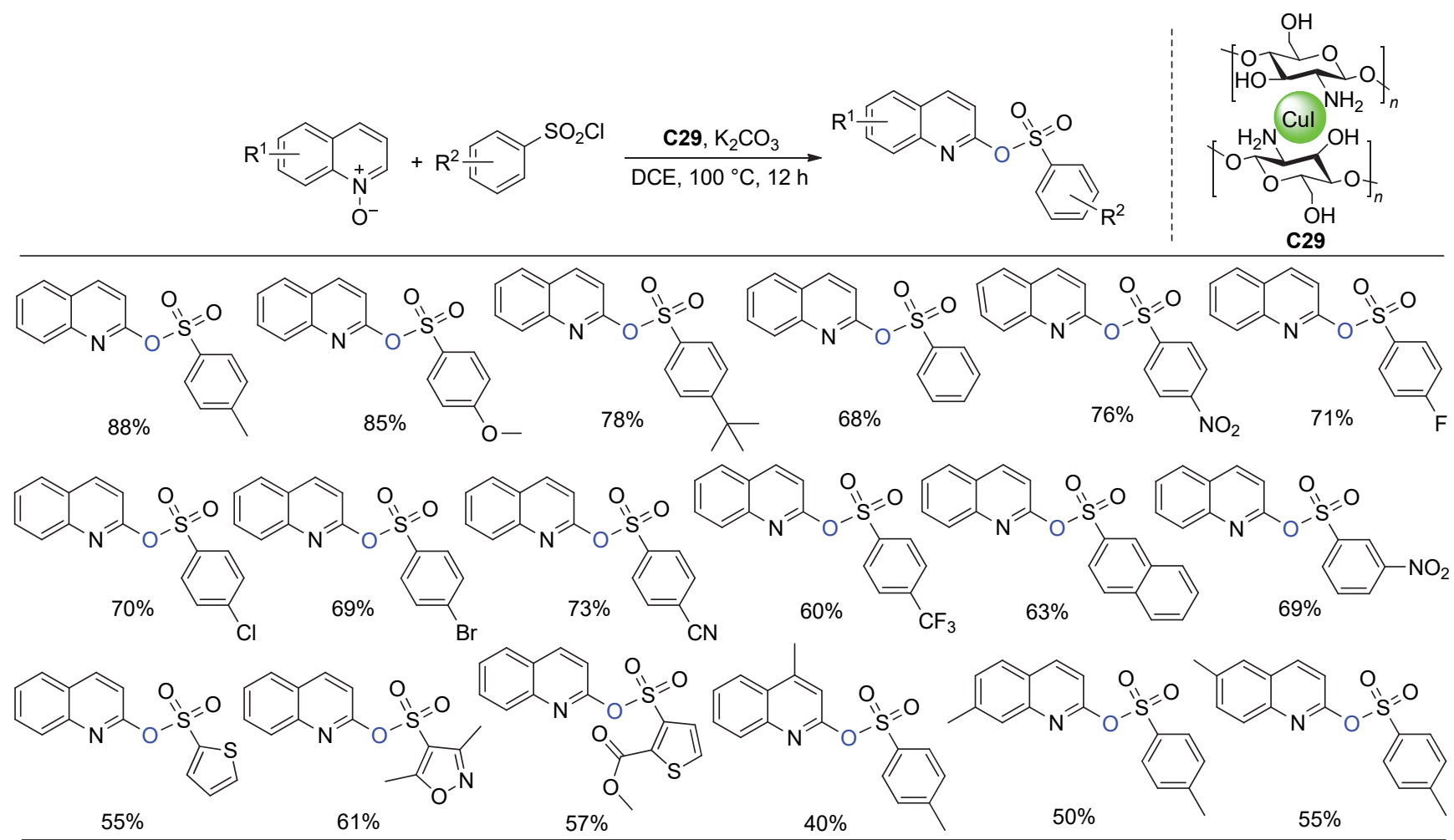

图式 $19 \mathrm{CS} @ \mathrm{CuI}(\mathbf{C 2 9})$ 催化的合成异喹啉 $N$-氧化物磺酸酯

Scheme 19 CS@CuI (C29) catalyzed synthesis of sulfonate esters of isoquinoline $N$-oxides 
以不同取代的苯磺酰氯为原料均能获得较好的产率, 且 催化剂可回收重复使用五次. 在该反应中, 磺酰氯底物 中取代基的诱导效应对反应活性有明显影响, 给电子基 才的底物能获得更高的产率, 而当磺酰氯结构中含有吸 电子基团或杂环化合物时, 产率有所下降. 作者推测产 率低的原因可能是吸电子基团不利于喹啉氮氧化物转 化为相应的芳基负离子.

\section{$2.4 \mathrm{C}-\mathrm{B}$ 键的构建}

有机硼化物是一类重要的合成中间体, 广泛应用于 药物制备及合成化学中, 其结构中的 $\mathrm{C}-\mathrm{B}$ 键可以通过 多种途径如 Suzuki-Miyaura 偶联、1,2-迁移反应、Petasis 反应、烯丙基硼化反应或氧化反应等转化为 $\mathrm{C}-\mathrm{O}$ 键、 $\mathrm{C}-\mathrm{N}$ 键和 $\mathrm{C}-\mathrm{C}$ 键. 许多关键药物均具有功能性硼基 团，如 talabostat、bortezomib、delanzomib 等. 因此，如 何实现有机嗍化物的制备, 高效构建 $\mathrm{C}-\mathrm{B}$ 键, 一直是 化学和材料领域中研究的热点.

2016 年, 朱䂞课题组 ${ }^{[53]}$ 制备了壳聚糖负载 $\mathrm{Cu}(\mathrm{OH})_{2}$ 催化剂 $\left(\mathrm{CS} @ \mathrm{Cu}(\mathrm{OH})_{2}, \mathbf{C 3 0}\right)$, 在纯水中实现了 $\alpha, \beta$-不饱 和化合物的喼加成反应(Scheme 20). 在该反应体系中, 需要添加 $6 \mathrm{~mol} \% \mathrm{~N}$-(2 吡啶基)苯甲酰胺, 以抑制反应过 程中铜的浸出. 该方法可以适用于一系列 $\alpha, \beta$-不饱和受 体, 包括 $\alpha, \beta$-不饱和酯和腈类化合物, 均能取得不错的 收率. 值得一提的是, 该催化剂在循环使用六次后, 依 然表现出优异的反应活性, 催化性能没有明显变化.

2018 年, 朱䂞课题组 ${ }^{[54]}$ 将壳聚糖(CS) 和聚乙烯醇 (PVA) 经戊二醛交联, 制备出复合膜后吸附 $\mathrm{Cu}(\mathrm{II})$, 再经
$\mathrm{NaBH}_{4}$ 还原得到膜负载的金属铜纳米粒子催化剂 $\mathrm{CP} @ \mathrm{Cu}$ NPs (C31). 利用该催化剂催化查尔酮和联喼的 嗍加成反应，通过对反应溶剂和催化剂的种类进行篮 选，得到最佳反应条件为使用丙酮和水的混合溶液作为 反应溶剂，室温下反应 $12 \mathrm{~h}$, 可以获得 $95 \%$ 的产率 (Scheme 21). 在此基础上, 作者对一系列苯环上不同取 代基的底物, 以及杂环噻吩类底物、位阻较大的菜环类 底物等的硼加成反应展开研究，结果显示都能以较高的 产率获得对应的目标产物, 特别是 $\alpha, \beta, \gamma, \delta$-不饱和酮类 底物可以选择性的进行 1,4-硼加成反应. 该催化剂具有 很高的催化活性和优良的反应选择性，整个反应过程中 条件温和，在水相中进行，无需额外添加碱，催化剂分 离回收方法简单，且再利用多次仍能保持较好的稳定 性，是一种高效、绿色、可回收的异相催化剂. 2021 年, 该课题组 ${ }^{[55]}$ 又利用纤维素负载 $\mathrm{CuI}$ 纳米粒子制备出催 化剂，与壳聚糖载体相比络合能力较弱，添加手性膦配 体的情况下, 在水相中实现了 $\alpha, \beta$-不饱和受体的不对称 硼加成反应.

\section{$2.5 \mathrm{C}-\mathrm{Si}$ 键的构建}

朱磊课题组 ${ }^{[56]}$ 进一步拓展壳聚糖负载铜催化反应 的类型，于 2018 年报道了一例 $\mathrm{C}-\mathrm{Si}$ 键的合成方法，有 机硅化合物在有机合成、材料科学和生物化学中具有很 多潜在的应用。该方法利用壳聚糖负载铜催化剂 $\left(\mathrm{CS} @ \mathrm{Cu}(\mathrm{acac})_{2}, \mathrm{C} 32\right)$, 在水相中实现了 $\alpha, \beta$-不饱和受体 的共轭硅烷化，为制备 $\beta$-硅取代化合物提供了一条绿色 有效的途径. 在最优条件下，各种不同取代的 $\alpha, \beta$-不饱
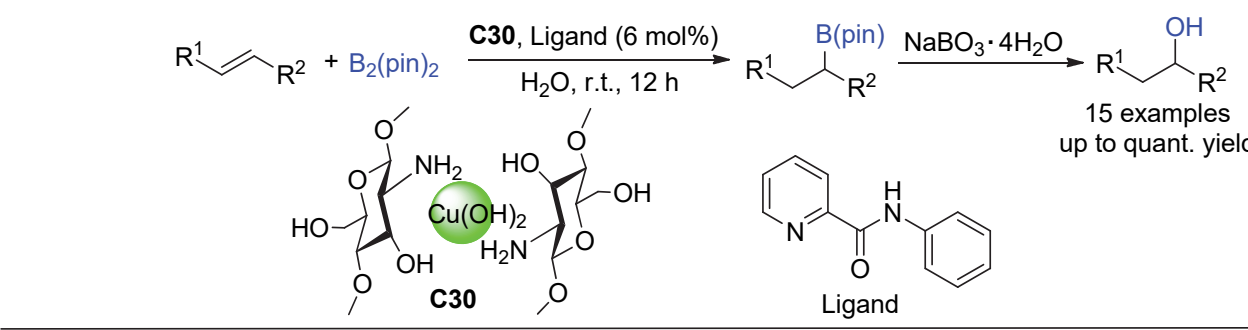

up to quant. yield
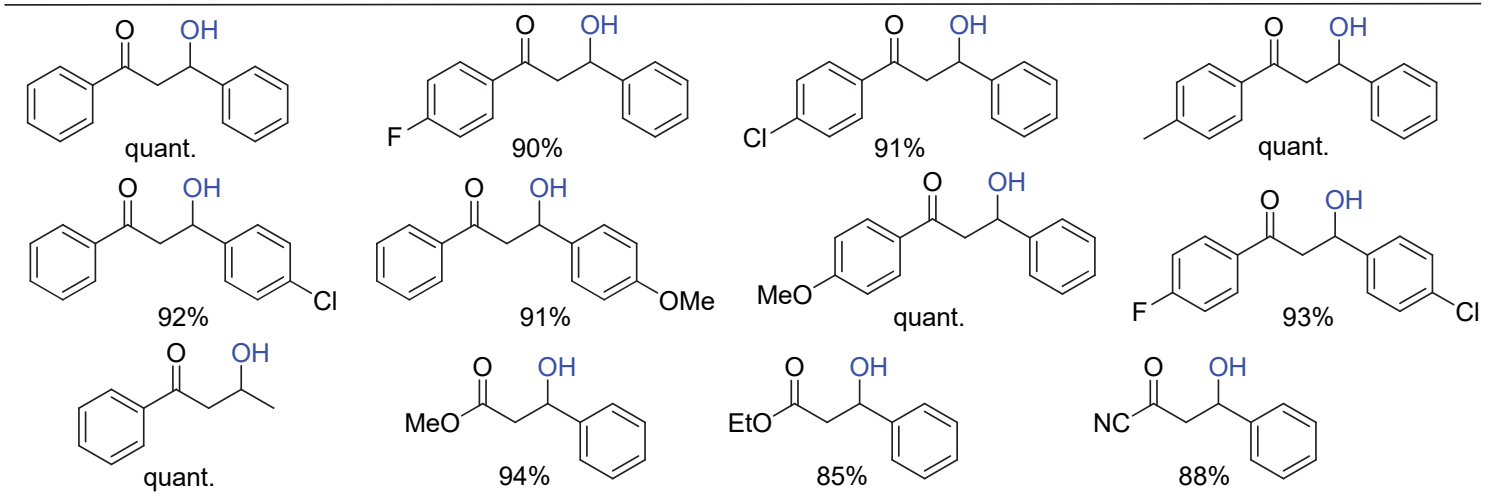

图式 $20 \mathrm{C30}$ 于水相中催化 $\alpha, \beta$-不饱和受体的嗍化反应

Scheme $20 \mathrm{C30}$ catalyzed borylation of $\alpha, \beta$-unsaturated acceptors in water 


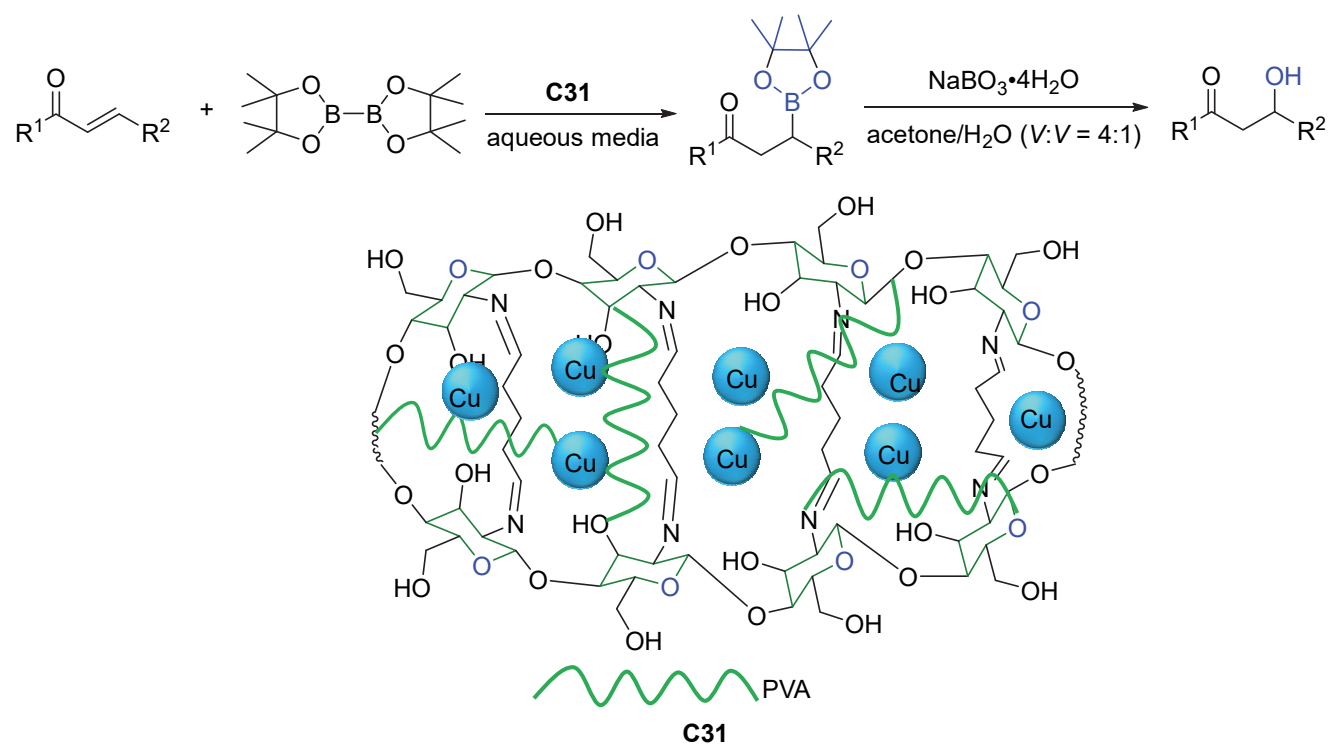

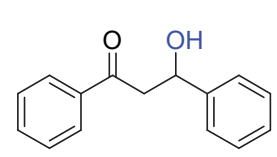

$95 \%$<smiles>Cc1ccc(C(O)CC(=O)c2ccccc2)cc1</smiles>

$95 \%$

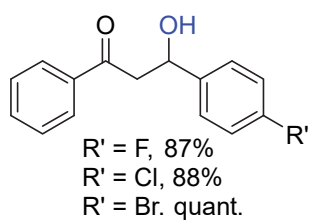<smiles>COc1ccc(C(O)CC(=O)c2ccccc2)cc1</smiles><smiles>O=C(CC(O)c1ccc(C(F)(F)F)cc1)c1ccccc1</smiles>

$\mathrm{R}^{\prime}=\mathrm{Br}$. quant.<smiles>COc1ccc(C(=O)CC(O)C(=O)c2ccccc2)cc1</smiles><smiles>COc1ccc(C(=O)CC(O)c2ccccc2C(=O)CC(O)c2ccc(C(=O)CC(O)c3ccc(C(=O)CC(O)c4cccc5ccccc45)cc3)cc2)cc1</smiles>

$85 \%$

$86 \%$ $\mathrm{R}^{\prime \prime}=\mathrm{OMe}$, quant<smiles>Cc1cccc(C(=O)CC(O)c2cccs2)c1</smiles><smiles>O=C(CC(O)c1cccs1)c1ccc(F)cc1</smiles><smiles>CC(=O)CC(O)c1ccccc1</smiles><smiles>CC(=O)CC(O)c1ccc(Cl)cc1</smiles><smiles>COc1ccc(C(O)CC(C)=O)cc1</smiles>

图式 21 复合薄膜负载铜 $\mathbf{C 3 1}$ 催化 $\alpha, \beta$-不饱和受体的硼化反应

Scheme 21 Composite film loaded with copper $\mathbf{C 3 1}$ catalyzed borylation of $\alpha, \beta$-unsaturated acceptors

和酮均能顺利转化为目标产物, 而 $\alpha, \beta, \gamma, \sigma$-不饱和化合 物可以选择性得到 1,4-加成产物(Scheme 22). 当在该体 系中添加 4-甲基吡啶时, 不仅可以作为碱加速反应进 行, 而且能有效防止在反应过程中金属铜的脱落. ICP 结果表明, 催化剂 C32 在循环使用六次后未检测到明显 铜的浸出, 产物依然能够以较高收率获得.

由上可知, 壳聚糖铜催化剂在构建 $\mathrm{C}-\mathrm{X}$ 键中有重 要的应用, 催化剂制备方法简单, 功能多样, 应用范围 从 $\mathrm{C}-\mathrm{N}$ 键和 $\mathrm{C}-\mathrm{O}$ 键, 拓展至近期 $\mathrm{C}-\mathrm{B}$ 键和 $\mathrm{C}-\mathrm{Si}$ 键的构建, 均能以中等以上收率得到目标产物. 在反应 结束后, 催化剂可以通过简单过滤或者磁性分离等方法 进行回收, 实现重复再利用.

\section{3 壳聚糖负载铜在点击化学中的应用}

“点击化学” 又称为 “链接化学”, 其主旨是通过小 分子的拼接, 快速可靠的完成分子的化学合成. 自 2001 年由 Sharpless ${ }^{[57]}$ 提出后, 点击化学广泛应用于药物开发 和生物医用材料领域 ${ }^{[58-62]}$. 鉴于点击化学应用广泛的特 性, 近年来, 多个课题组相继报道了壳聚糖负载铜催化 剂在点击反应中的应用.

2009 年, Quignard 课题组 ${ }^{[63]}$ 将 $\mathrm{Cu}(\mathrm{I})$ 负载到多种类 型席夫碱修饰的壳聚糖上, 制备出一系列壳聚糖席夫碱 铜催化剂(CS@CuOTf, C33 $\sim \mathbf{C 4 3}$ ) (Scheme 23). 经过反 应测试比较, 篮选出最优催化剂为 $\mathbf{C 4 2}$, 该催化剂在用 量为 $0.1 \mathrm{~mol} \%$ 时, 以乙醇或水为反应溶剂, 在不同底物 


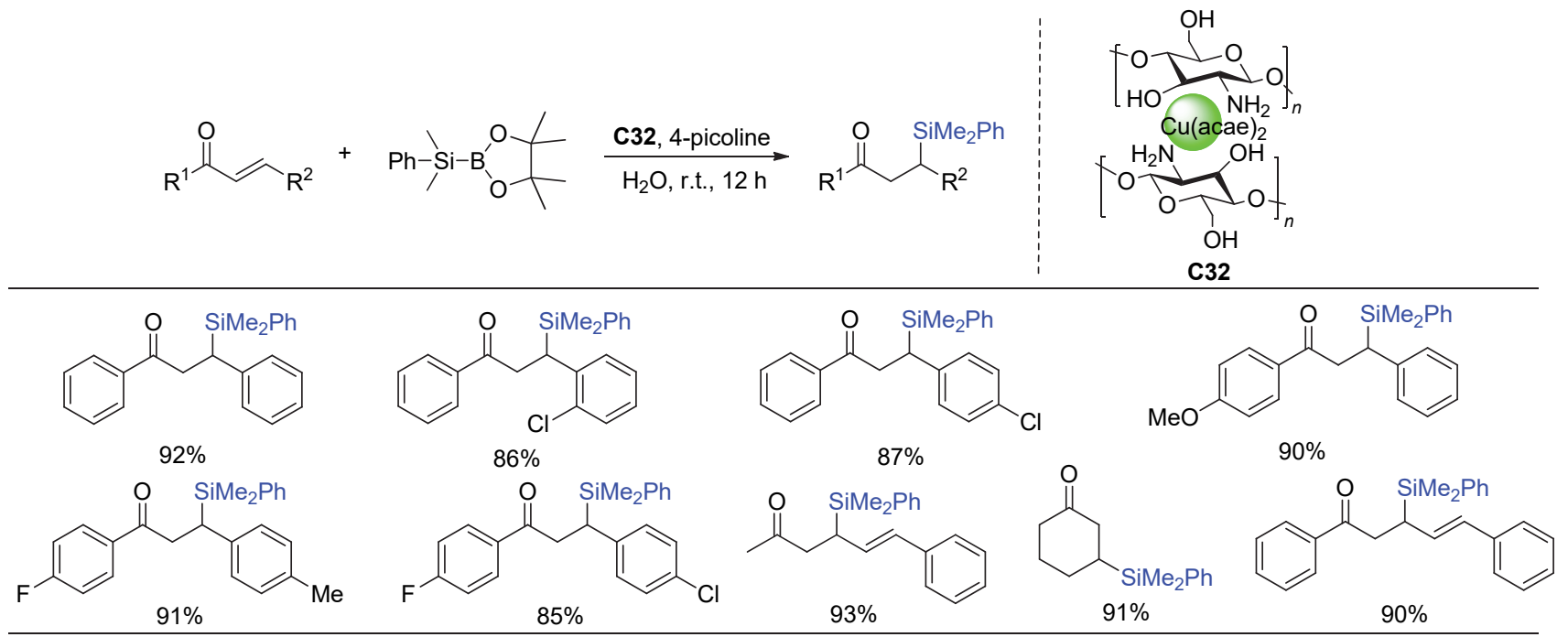

图式 $22 \mathrm{C32}$ 催化 $\alpha, \beta$-不饱和受体的共轭硅烷化

Scheme 22 C32 catalyzed conjugate silylation of $\alpha, \beta$-unsaturated acceptors
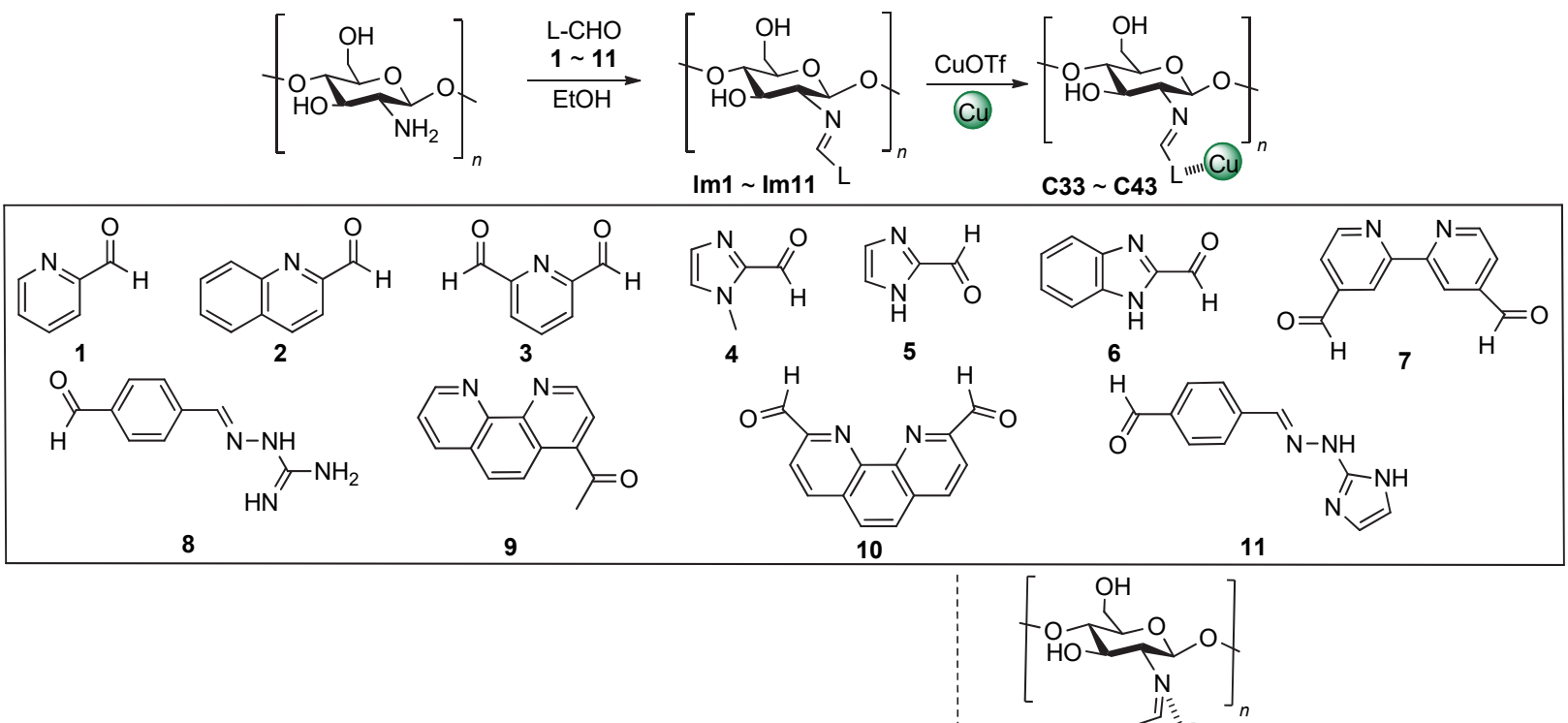

$$
\mathrm{R}-\mathrm{N}_{3}+\equiv \mathrm{R}^{\prime} \quad \underset{70^{\circ} \mathrm{C}, 12 \mathrm{~h}}{\mathrm{C42}(0.1 \mathrm{~mol} \%)} \mathrm{R}-\mathrm{N}_{\mathrm{R}^{\prime}}^{\mathrm{N}=\mathrm{N}}
$$
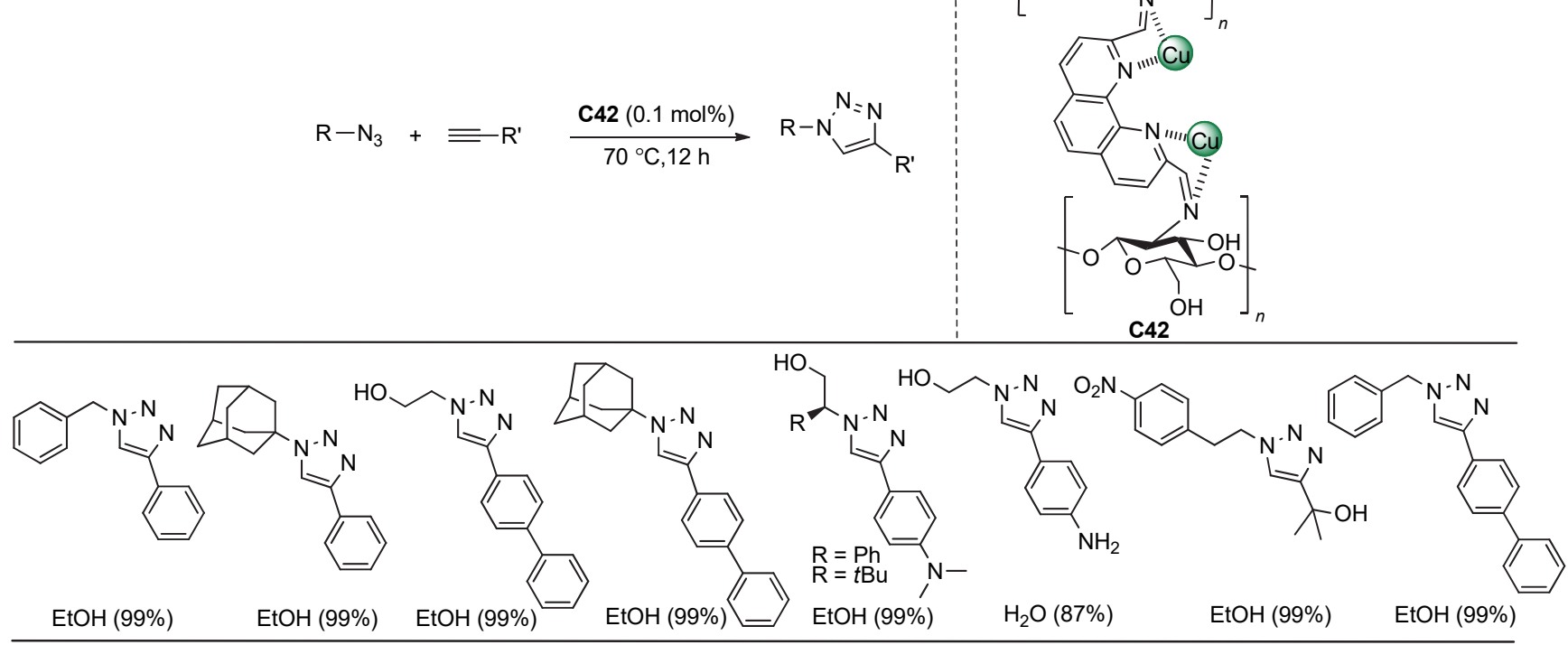

图式 $23 \mathbf{C 4 2}$ 催化 Huisgen[3+2]环加成反应

Scheme 23 C42 catalyzed Huisgen [3+2] cycloaddition 
的 Huisgen[3+2]环加成反应中均表现出较高的催化活 性(87\% 99\%) (Scheme 23). 实验结果表明, 壳聚糖席 夫碱结构对铜盐的强螯合能力有利于催化叠氮与炔烃 的[3+2]环加成反应(点击反应).

2011 年, Cravotto 课题组 ${ }^{[64]}$ 报道了一种通过超声波 辅助法来合成固体负载型 $\mathrm{Cu}(\mathrm{I})$ 催化剂的方法, 该方法 是以六亚甲基二异氧酸酯为原料, 制备出交联壳聚糖衍 生物, 并利用超声去除壳聚糖衍生物中的气泡, 从而打 破团聚现象以获得大小规则的纳米球 CS@ $\mathrm{Cu}(\mathrm{I})(\mathbf{C 4 4})$.

FT-IR、XPS、ICP-MS、TGA 等测试表明铜成功负载到 壳聚糖上, 负载量为 $1.10 \mathrm{~mol} \%$. 作者进一步将催化剂 C44 应用于偶极环加成反应, 实验结果表明, 该反应能 够在较短的时间 (90 min) 和较低的温度 $\left(50{ }^{\circ} \mathrm{C}\right)$ 下完成, 且以高产率 $(>86 \%$, Scheme 24$)$ 得到目标产物. 反应结 束后, 回收后的催化剂经二噁烷、二氯甲烷洗涤后，可 重复使用三次, 活性损失小, 而且 ICP 测试表明反应前 后催化剂中铜含量几乎相同, 没有明显铜的浸出现象.

2013 年, Varma 课题组 ${ }^{[65}$ 将 $\mathrm{CuSO}_{4}$ 直接加入壳聚糖 悬浮液中摚拌, 制备出壳聚糖负载硫酸铜催化剂 $\left(\mathrm{CS} @ \mathrm{CuSO}_{4}, \mathrm{C} 45\right)$, 并将其应用于水相中催化叠氮化物 和末端炔烃之间的 1,3-偶极环加成(CuAAC)反应, 以优 异的收率(93\% 99\%)得到目标产物(Scheme 25). 该方 法明显提升了整个催化体系的反应活性，除脂肪族叠氮 化物外, 大多数底物在反应中均能快速进行, 且在循环 使用五次后，催化效率仍维持在 $95 \%$.

2014 年, 熊兴泉课题组 ${ }^{[66]}$ 将壳聚糖与 $N-(2$-氨乙 基)-3-氨丙基三乙氧基硅烷(AAPTS)反应制备胺基功能 化的壳聚糖(CS-AAPTS), 然后将 CS-AAPTS 与 $\mathrm{CuBr}$ 进 行络合得到负载型催化剂(CS-AAPTS@ $\mathrm{CuBr}, \mathrm{C46})$. 利 用微波辐射技术以及 “一锅法” 合成策略, 以
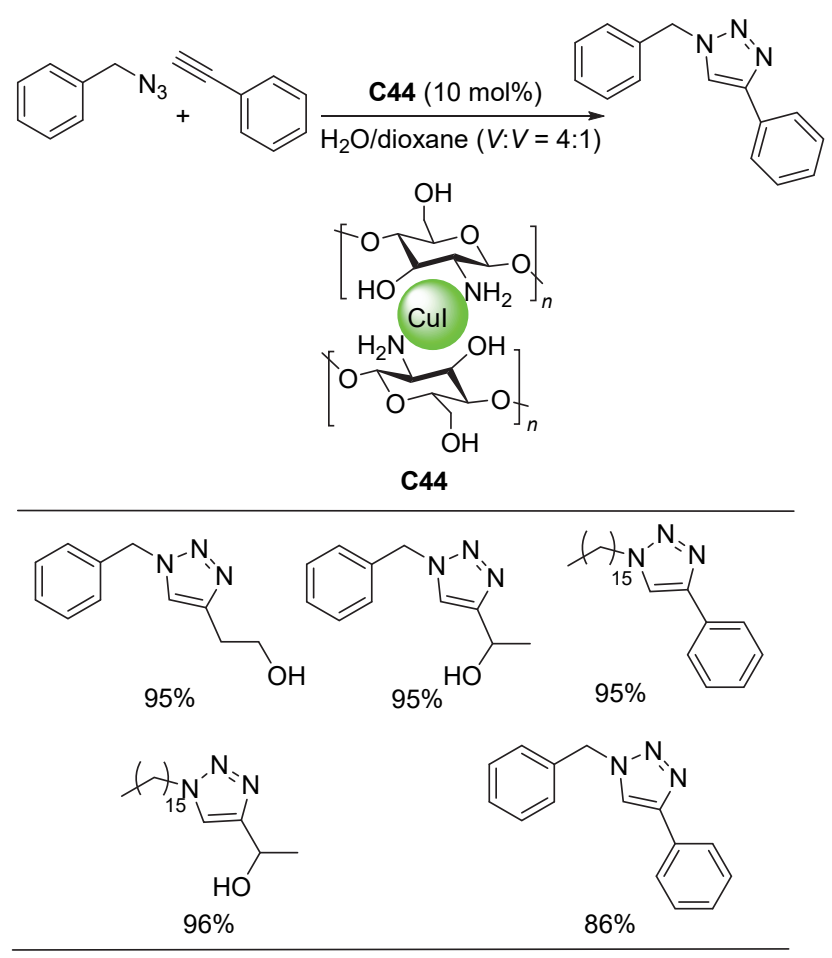

图式 24 交联的 $\mathrm{CS} @ \mathrm{Cu}(\mathrm{I})(\mathbf{C 4 4})$ 催化合成三唑 Scheme 24 Synthesis of triazole catalyzed by cross-linked $\mathrm{CS} @ \mathrm{Cu}(\mathrm{I})(\mathbf{C} 44)$

CS- AAPTS@CuBr 为催化剂催化有机炔、卤代烷以及 $\mathrm{NaN}_{3}$ 之间的环加成反应，高效率(88\% 94\%)地合成出 一系列 1,2,3-三唑类化合物(Scheme 26). 该催化剂在该 反应中具有高催化性和铜浸出率低的优点, 整个反应过 程条件温和、反应时间短、产率优良且后处理简单, 并 且能够以 $94 \%$ 的收率, 大于 $10 \mathrm{~g}$ 规模得到目标产物.

2015 年, Sarma 课题组 ${ }^{[67]}$ 开发了一种简单、高效的 叠氮化物和炔烃 $[3+2]$ 环加成的多相催化反应体系. 在
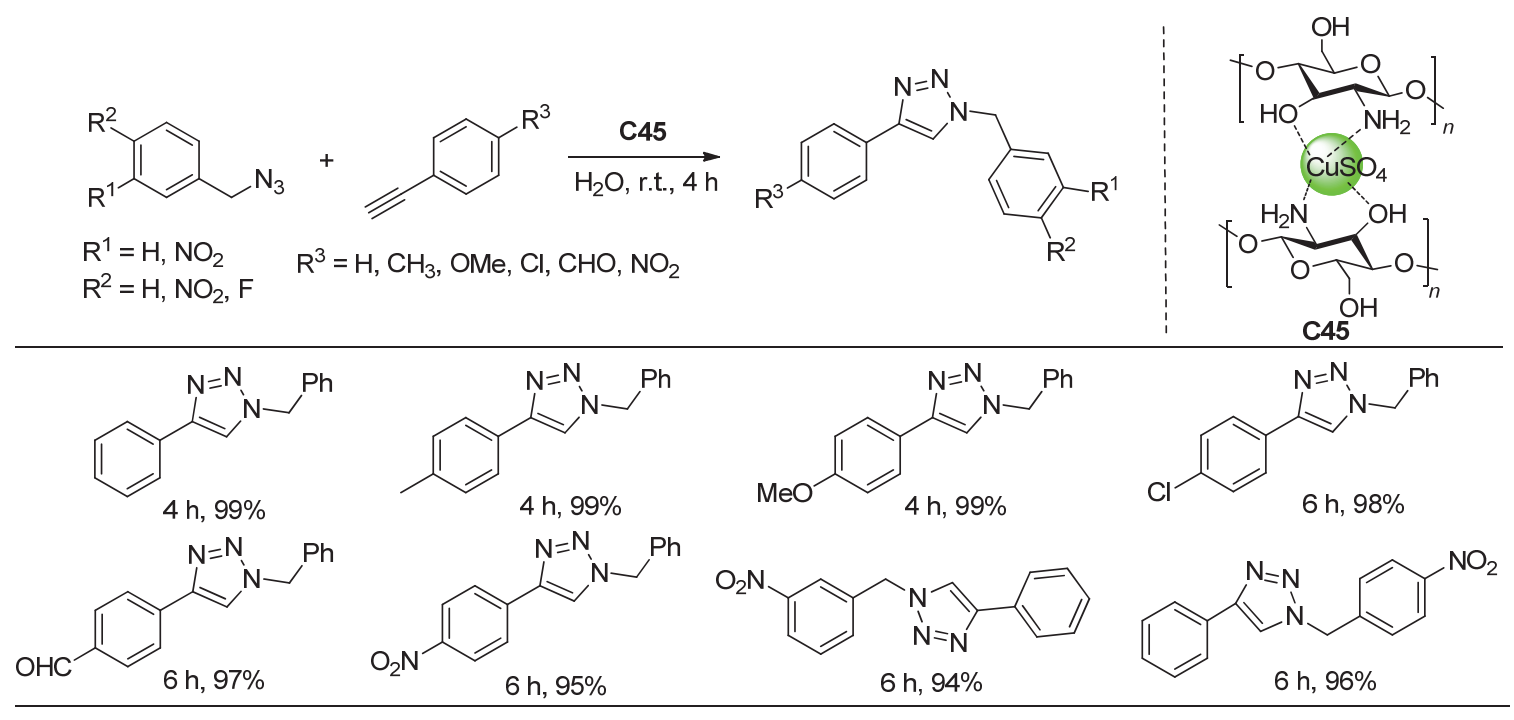

图式 $25 \mathrm{CS} @ \mathrm{CuSO}_{4}(\mathbf{C 4 5})$ 催化叠氮苄与苯乙炔的偶极环加成反应

Scheme $25 \mathrm{CS@CuSO}$ (C45) catalyzed dipolar cycloaddition of benzyl azide and phenyl acetylene 


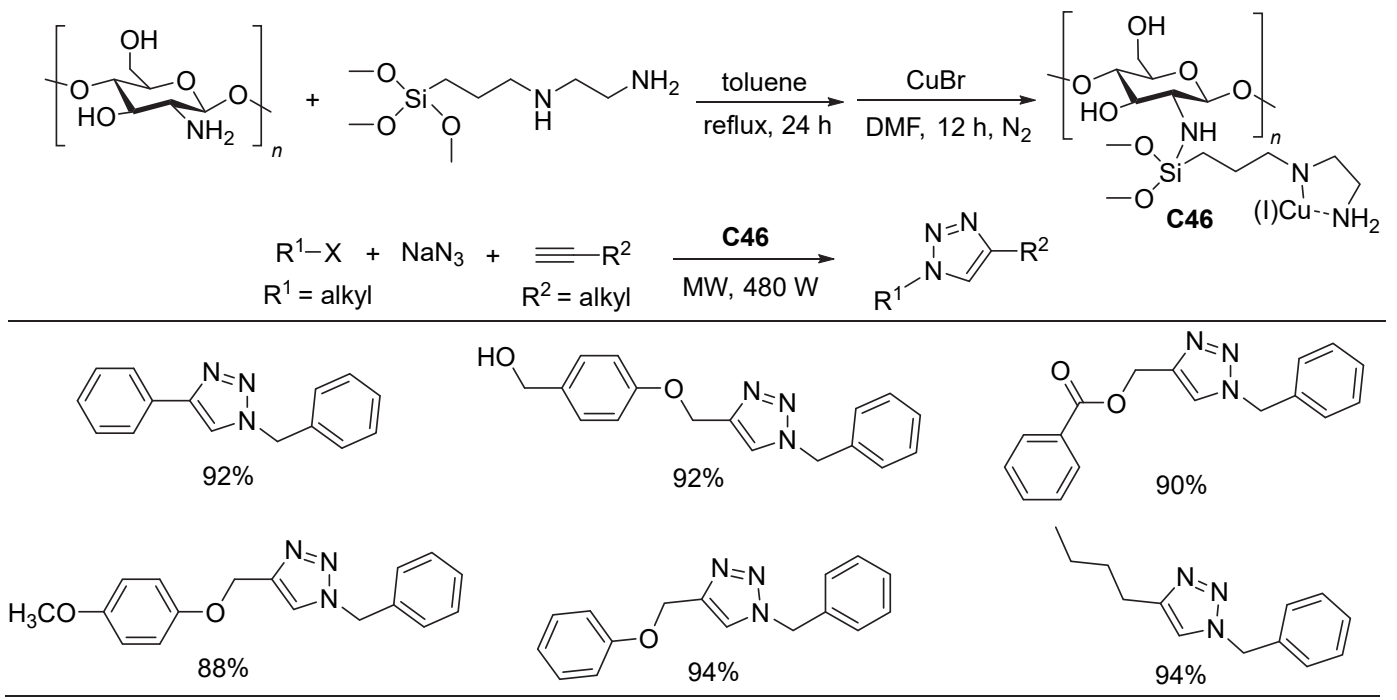

图式 26 CS-AAPTS@CuBr (C46)催化合成 1,2,3-三唑

Scheme 26 CS-AAPTS@CuBr (C46) catalyzed synthesis of 1,2,3-trazoles

$\mathrm{pH}=12$ 的条件下, 采用亚铁离子和铁离子共沉淀生成 磁性 $\mathrm{Fe}_{3} \mathrm{O}_{4}$, 随后包覆铜离子吸附在壳聚糖外层, 最后 用嗍氢化钠将铜离子还原生成 $\mathrm{Cu}^{0}$, 即可得到壳聚糖稳 定铜的氧化铁纳米复合材料 $\left(\mathrm{CS} / \mathrm{Fe}_{3} \mathrm{O}_{4} @ \mathrm{Cu}, \mathrm{C} 47\right)$. 该异 相催化反应体系具有底物适用范围广, 可与各种叠氮化 物和炔烃(包括内炔烃)反应, 并具有很高的区域选择性, 且仅形成 1,4-双取代的 1,2,3-三唑的区域异构体(Scheme 27). 值得一提的是, 反应结束后利用磁性可以简便快 速回收 $\mathrm{CS} / \mathrm{Fe}_{3} \mathrm{O}_{4} @ \mathrm{Cu}$ 催化剂, 重复使用四次后, 其活性
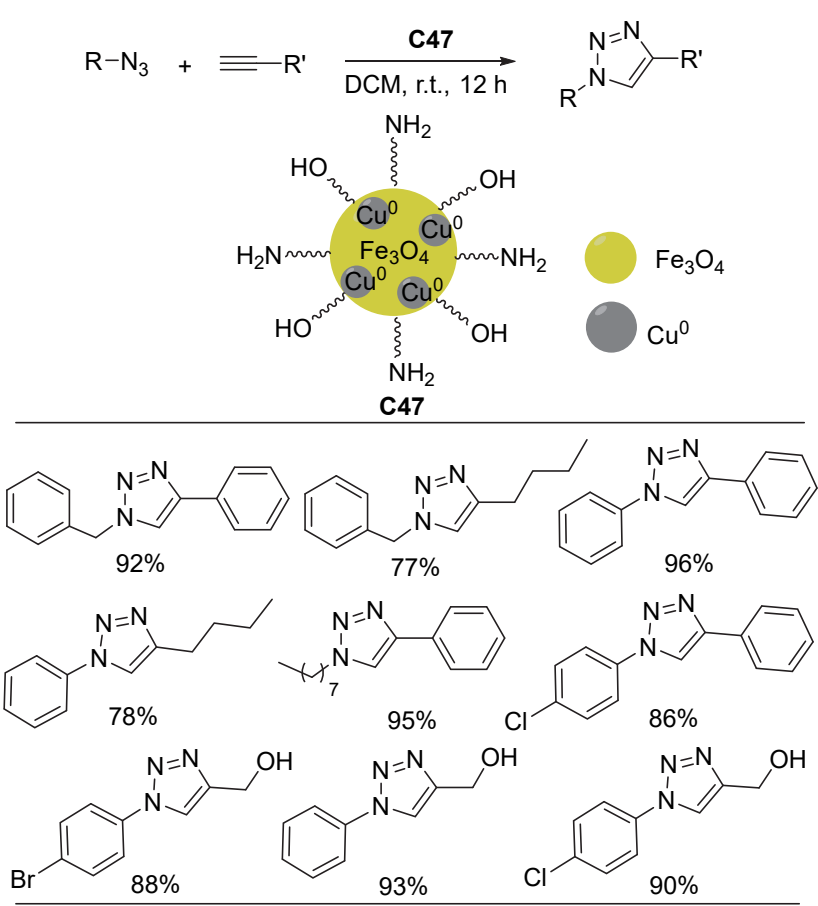

图式 $27 \mathrm{CS} / \mathrm{Fe}_{3} \mathrm{O}_{4} @ \mathrm{Cu}(\mathbf{C} 47)$ 催化叠氮一炔环加成反应 Scheme 27 CS/Fe $\mathrm{F}_{4} @ \mathrm{Cu}(\mathbf{C 4 7})$ catalyzed azide-alkyne cycloaddition
没有显著降低.

2015 年, Nageswar 课题组 ${ }^{68}$ ] 通过壳聚糖吸附 $\mathrm{CuSO}_{4}$ 制备催化剂 $\mathrm{CS} @ \mathrm{CuSO}_{4}(\mathbf{C 4 8})$. 实验研究表明该催化剂 可以促进芳基硼酸与末端炔烃、叠氮化钠在水中进行一 锅法反应, 通过 1,3-偶极环加成高效得到 1,2,3-三氮唑 偶联产物(Scheme 28)。此外，催化剂在重复使用五次
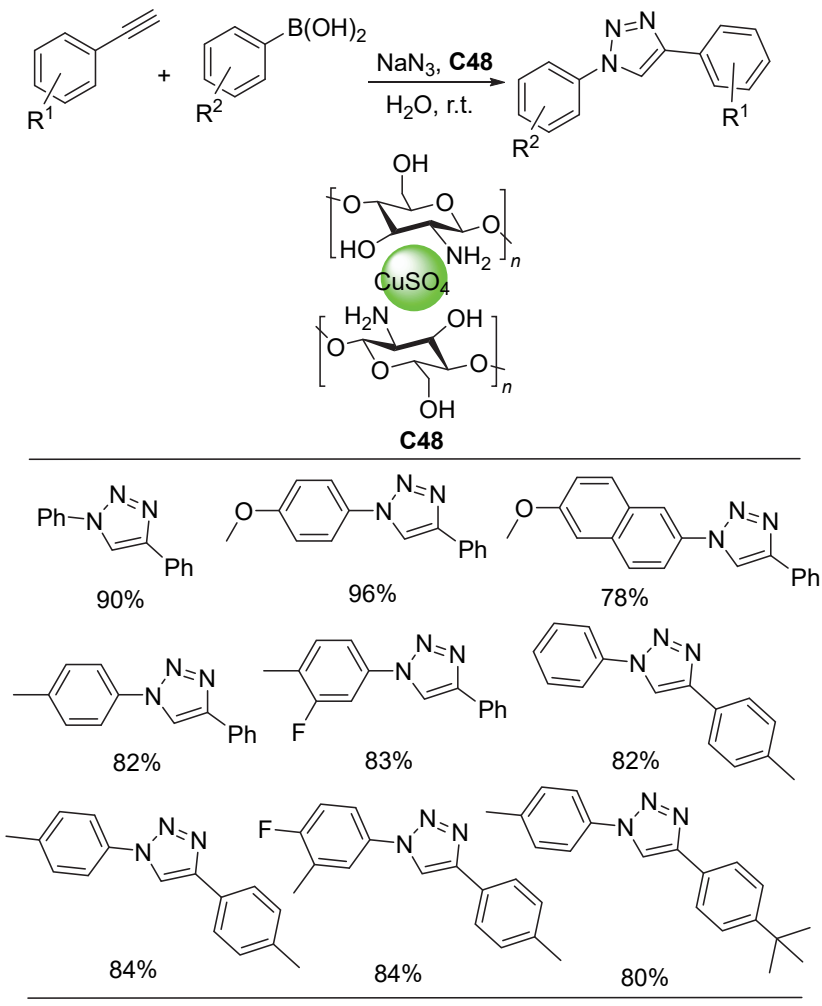

图式 $28 \mathrm{CS} @ \mathrm{CuSO}_{4}(\mathbf{C 4 8})$ 在水中催化合成 1,4-二取代-1,2,3三唑

Scheme 28 Synthesis of 1,4-disubstituted-1,2,3-triazolesusing using $\mathbf{C 4 8}$ as catalyst in water 
后，依然能保持较高的催化活性.

2017 年, Amini 课题组 ${ }^{[69]}$ 首先采用原位法制备出磁 性纳米材料, 负载铜离子后, 得到一种新型的磁性壳聚 糖铜/凝胶纳米复合材料 C49. 作者随后将合成出的 $\mathbf{C 4 9}$ 作为催化剂, 催化卤代物、末端炔烃以及叠氮化钠在水 相中的反应，在 $70{ }^{\circ} \mathrm{C}$ 时能够以高收率(54\% 97\%)得到 目标 1,2,3-三氮唑化合物(Scheme 29). 因此, 该磁性材 料是一种高性能且环境友好的催化剂.
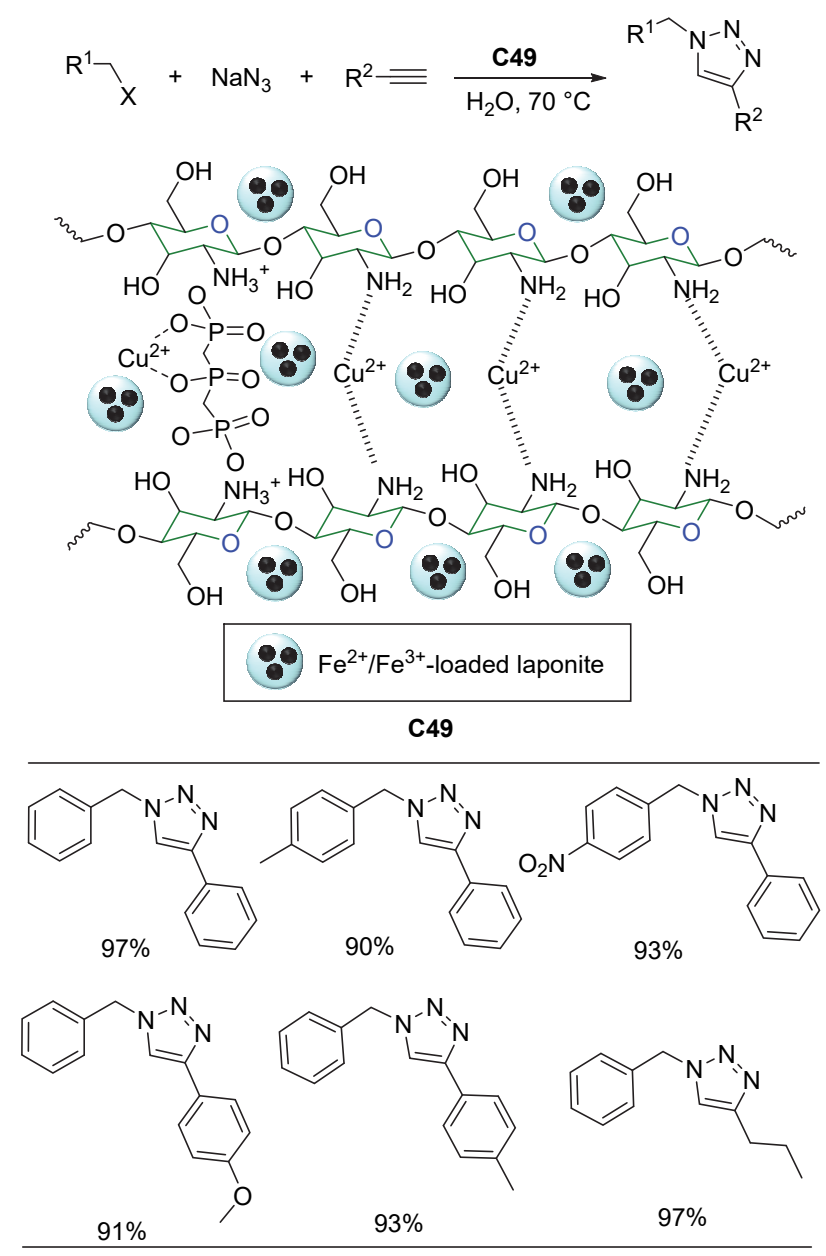

图式 29 磁性壳聚糖铜/凝胶纳米复合材料 $\mathbf{C 4 9}$ 催化卤化物与 末端炔烃的环加成反应

Scheme 29 Cycloaddition of alkyl halides with terminal alkynes in the presence of $\mathrm{Cu}^{\mathrm{II}}$-magnetic chitosan nanocomposite C49

2018 年, Vincent 课题组 ${ }^{[70]}$ 利用二苯甲酮结构(BP) 的光引发性质, 制备了一种负载于壳聚糖粉末上的异相 $\mathrm{Cu}(\mathrm{II})$ 光催化剂(CS@CuBP, C50), 并将其应用于催化叠 氮烷烃环加成反应. 作者详细报道了催化剂的制备过 程, 首先将文献已报道过的铜一邻苯甲酰苯甲酸甲酯二 聚体化合物与去乙酰化后的壳聚糖溶液在 $\mathrm{THF} / \mathrm{H}_{2} \mathrm{O}$ 混 合溶剂中反应. 在上述过程中, 优化反应条件, 使得每 克壳聚糖上氨基含量约为 $5 \mathrm{mmol}$, 壳聚糖上氨基与金
属铜盐最佳比值约为 25 . ICP 测试结果显示, 铜的负载 量为 $0.18 \mathrm{mmol} / \mathrm{g}$. 通过此条件制备的催化剂在紫外光 谱为 300 400 nm 区域可发生 $\mathrm{n}-\pi$ 电子跃迁，此条件下 可以有效提高 $\mathrm{Cu}(\mathrm{II})$ 离子活性. 因此，在紫外灯照射下， 该催化剂在点击反应中的催化性能显著提升，产物收率 均能维持在 $80 \%$ 以上(Scheme 30). 此种异相催化剂在反 应中铜浸出率低, 易于直接过滤, 可再次回收利用.

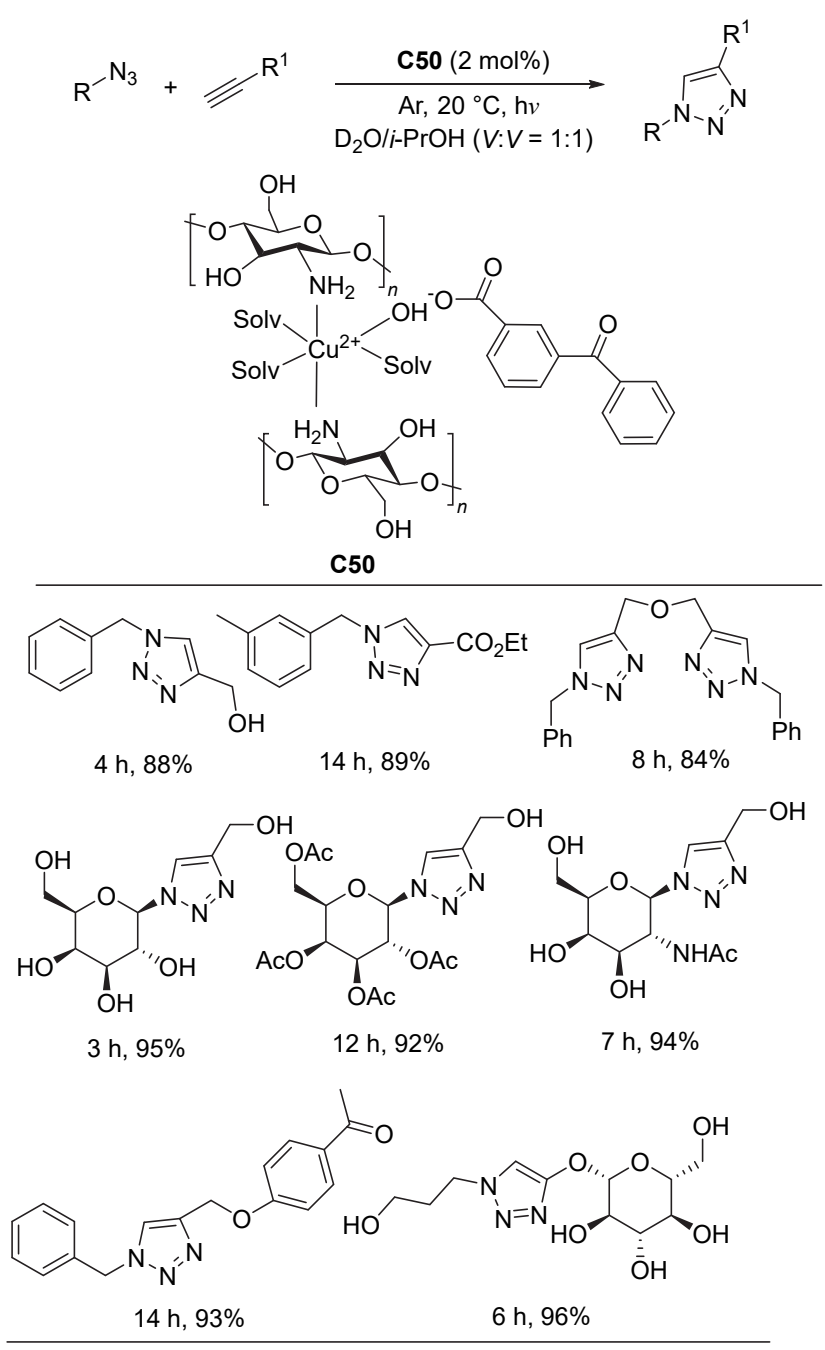

图式 $30 \mathrm{CS} @ \mathrm{CuBP}(\mathbf{C 5 0})$ 催化的叠氮烷基环加成 Scheme 30 CS@CuBP (C50) catalyzed azide-alkyne cycloaddition

点击化学反应具有产率高、原子经济、应用较广、 立体选择性强等优点, 产物种类多样, 在新药开发中具 有重要的研究价值. 作为推动点击化学发展的重要角 色, 催化剂的选择至关重要, 壳聚糖载体以其廉价低 毒、来源广泛的特性, 在该类反应中起着关键作用.

\section{4 壳聚糖负载铜在氧化还原反应中的应用}

硫醚氧化产物亚砜以及砜是重要的化学品，在药物 和有机反应中间体等方面得到广泛应用，目前应用较多 
的催化剂主要是钒体系和钛体系 ${ }^{[71]}$. 近年来, 出现了将 壳聚糖修饰制备出磁性壳聚糖, 再与铜盐配位得到磁性 壳聚糖负载铜催化剂, 并应用于硫醚氧化反应中, 从而 实现以双氧水为氧化剂的绿色催化反应过程.

\section{1 氧化反应}

2012 年, David 课题组 ${ }^{[72]}$ 首先制备出壳聚糖席夫碱, 吸附 $\mathrm{Cu}(\mathrm{OAc})_{2}$ 后再添加配体, 通过络合制备出一类新 型壳聚糖负载 salen $\mathrm{Cu}$ 配合物型催化剂 C51 (Scheme 31). 作者利用公式计算出壳聚糖席夫碱的氨基取代度 为 0.46 , 红外及紫外光谱结果表明金属铜成功负载到改 性后的壳聚糖上. 该催化剂在 $70{ }^{\circ} \mathrm{C}$ 下, 以 $\mathrm{H}_{2} \mathrm{O}_{2}$ 为氧化 剂, 能以 $83 \%$ 的收率催化烷烃的氧化反应. 值得一提的 是, 该催化剂可通过简单的过滤实现分离, 并能重复使 用四次.
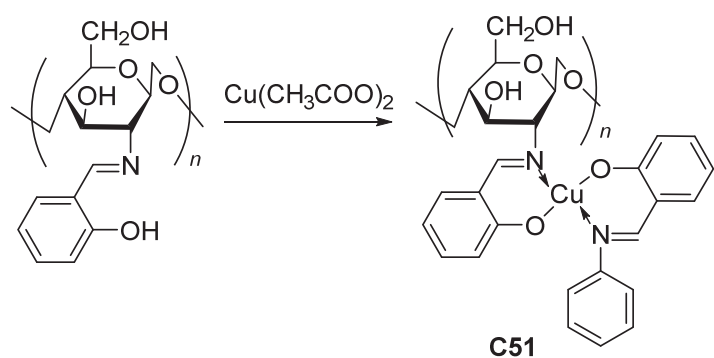

图式 31 壳聚糖负载 salen $\mathrm{Cu}$ 配合物型催化剂 C51 结构 Scheme 31 Structure of chitosan supported Salen $\mathrm{Cu}$ complex catalyst $\mathbf{C 5 1}$

2016 年, Naghipour 课题组 ${ }^{[73]}$ 通过将 $\mathrm{Cu}(\mathrm{II})$ 与包覆 $\mathrm{Fe}_{3} \mathrm{O}_{4}$ 磁性纳米颗粒的壳聚糖共价接枝, 成功制备出一 种对环境友好的、可磁性回收的新型纳米催化剂 $\left(\mathrm{Fe}_{3} \mathrm{O}_{4} /\right.$ $\mathrm{CS} @ \mathrm{Cu}, \mathrm{C52}$ ). 作者利用该催化剂在温和的反应条件 下, 以 $\mathrm{H}_{2} \mathrm{O}_{2}$ 为氧化剂, 将不同取代硫醚氧化成相应的亚 砜化合物(Scheme 32), 且具有优异的产率(92\% 98\%). 该小组为了评估其可重复使用性能, 通过磁力吸附, 可 以很简便地从反应残余物中分离出催化剂, 然后在相同 条件下进一步添加适量底物后即用于下次反应, 即使循 环四个反应周期, 催化剂活性也没有明显的损失, 有望 实现大规模的应用. 此外, TGA 分析表明, 该磁性纳米 催化剂具有较高的热稳定性.

2018 年, Naghipour 课题组 ${ }^{[74]}$ 在之前工作基础上, 将磁性 $\mathrm{Fe}_{3} \mathrm{O}_{4}$ 与壳聚糖共价接枝, 与醛类物质反应合成 席夫碱配体, 再与铜盐络合得到具有磁性分离功能的吡 咯醛酮络合物 C53. 随后，作者仅用 $0.31 \mathrm{~mol} \%$ 催化剂, 在室温下硫醚底物以 $92 \% \sim 97 \%$ 的极高产率转化为亚 砜. 反应结束后, C53 易于通过磁性从反应混合物中分 离出来, 从而实现多次循环 (Scheme 33). 相比之前的工 作，该体系不仅简化了催化剂结构，还提高了反应活性.

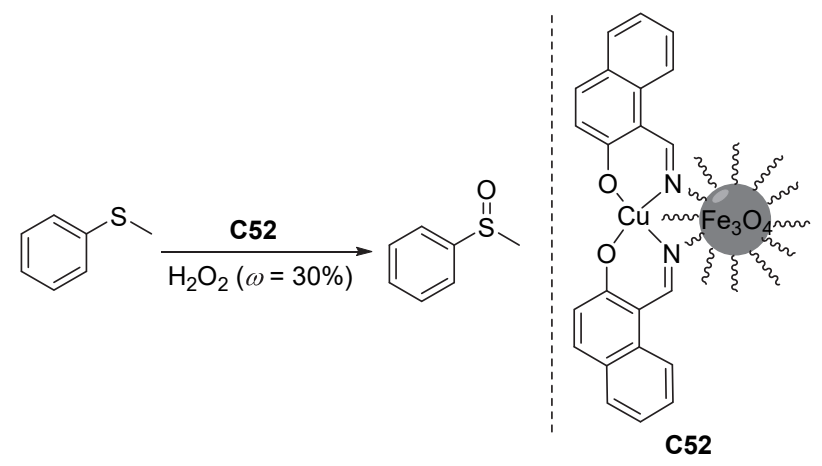<smiles>CS(=O)c1ccccc1</smiles><smiles>O=S(Cc1ccccc1)Cc1ccccc1</smiles>
$\mathrm{C}_{12} \mathrm{H}_{25} \stackrel{\mathrm{O}}{\mathrm{S}}$ $95 \%$<smiles>COC(=O)CCS(C)=O</smiles><smiles>O=S(CCO)c1ccccc1</smiles><smiles>CS(=O)Cc1ccco1</smiles>

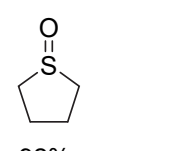<smiles>O=S(Cc1ccccc1)c1ccccc1</smiles><smiles>Cc1ccc(S(C)=O)cc1</smiles>

图式 $32 \quad \mathrm{Fe}_{3} \mathrm{O}_{4} / \mathrm{CS} @ \mathrm{Cu}(\mathbf{C 5 2})$ 催化硫醚氧化反应 Scheme $32 \quad \mathrm{Fe}_{3} \mathrm{O}_{4} / \mathrm{CS} @ \mathrm{Cu}(\mathbf{C 5 2})$ catalyzed sulfur oxidation reaction

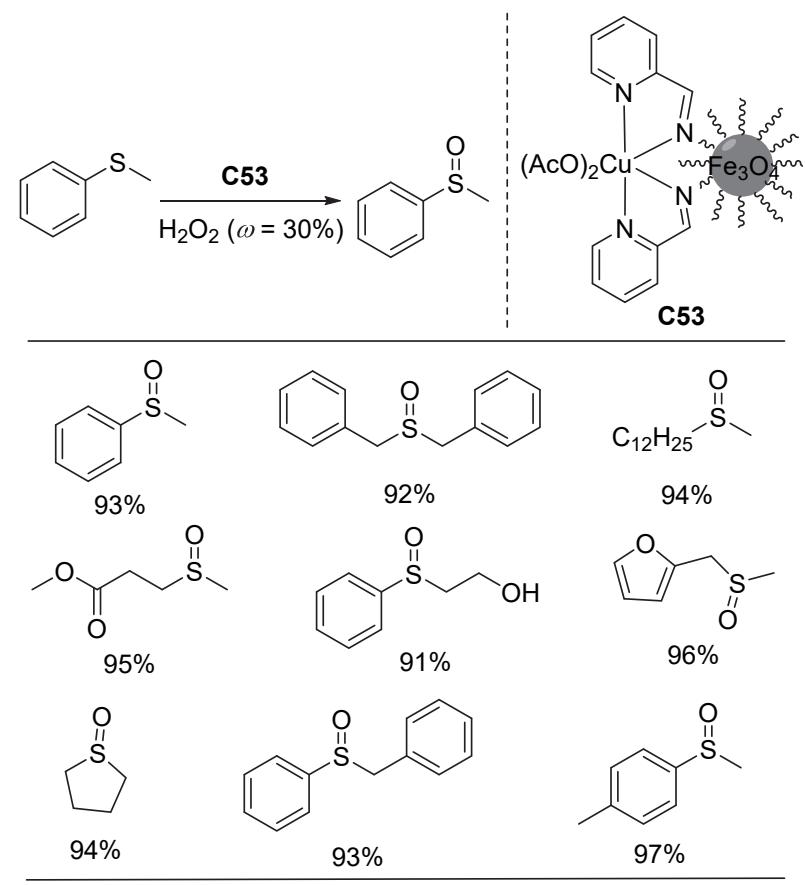

图式 33 Schiff- $\mathrm{Fe}_{3} \mathrm{O}_{4} / \mathrm{CS} @ \mathrm{Cu}(\mathbf{C 5 3})$ 催化硫醚氧化反应 Scheme 33 Schiff- $\mathrm{Fe}_{3} \mathrm{O}_{4} / \mathrm{CS} @ \mathrm{Cu}(\mathbf{C 5 3})$ catalyzed sulfur oxidation reaction 


\section{2 还原反应}

2017 年, Fajardo 课题组 ${ }^{[75]}$ 采用交联的方法制备了 壳聚糖 $(\mathrm{CS})$ /聚乙烯醇(PVA)薄膜, 作者首先将壳聚糖溶 解在醋酸溶液中室温摚拌 $5 \mathrm{~h}$, 聚乙烯醇溶解在 $80{ }^{\circ} \mathrm{C}$ 水 中. 随后, 上述两种溶液采用磁力摚拌器混合均匀, 再 滴加戊二醛溶液进行交联, 倒入培养血中进行成膜, 烘 干, 剥离, 洗涤直至形成中性薄膜 CP. 最后, 将上述薄 膜浸泡在 $\mathrm{CuCl}_{2} \cdot 2 \mathrm{H}_{2} \mathrm{O}$ 溶液中吸附铜离子, 经 $\mathrm{NaBH}_{4}$ 还 原后得到 $\mathrm{CP}$ 膜负载铜纳米粒子催化剂 $(\mathrm{CP} @ \mathrm{Cu} \mathrm{NPs}$, C54). 该催化剂具有良好的机械性能和耐化学性, 在使 用和回收过程中均易于处理, 当将其应用于硝基苯还原 为苯胺(Scheme 34), 经过六次循环使用, 仍然保持着优 异的催化性能. 此工作中的催化剂可以有效地作为昂贵

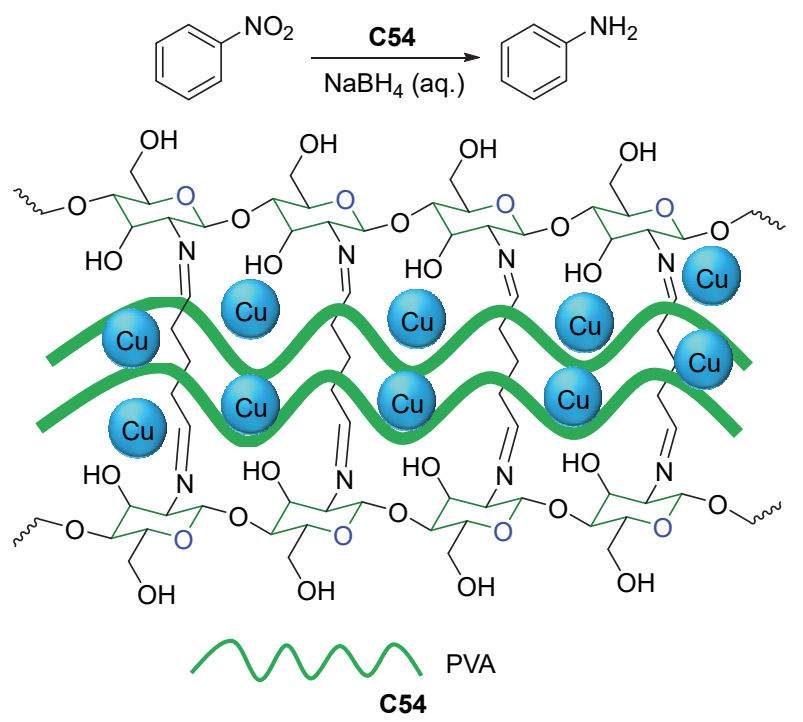

图式 34 壳聚糖/聚乙烯醇膜负载铜(C54)催化还原硝基苯 Scheme 34 Catalytic reduction of NB to AN in the presence of $\mathrm{NaBH}_{4}$ by $\mathbf{C 5 4}$
金属的替代物，对芳香族硝基化合物还原为芳香族胺的 研究具有指导意义.

2018 年, Khan 课题组 ${ }^{[76]}$ 以壳聚糖-二氧化硅纳米复 合纤维为模板，制备出金属纳米粒子负载纤维，然后用 金属盐溶液和 $\mathrm{NaBH}_{4}$ 处理，得到负载不同金属 $(\mathrm{Cu} 、 \mathrm{Co} 、$ $\mathrm{Ag} 、 \mathrm{Ni}$ )的催化剂(Scheme 35). 通过对 4-硝基苯胺还原 反应的测试, 在各类壳聚糖负载型催化剂中, 金属 $\mathrm{Cu}$ 纳米粒子负载的脱乙酰化壳聚糖 $(\mathrm{CH}) /$ 二氧化硅材料 $\left(\mathrm{CH}-\mathrm{SiO}_{2} @ \mathrm{Cu} \mathbf{C 5 5}\right)$ 具有最佳的催化性能, 而且其在硝 基酚的还原反应、刚果红的脱色反应中均具有较好的催 化效果，展现出广泛的应用前景.

2019 年, 郭燕课题组 ${ }^{[77]}$ 采用简便的化学还原法制 备了壳聚糖(CS)改性氧化亚铜 $\left(\mathrm{CS} @ \mathrm{Cu}_{2} \mathrm{O}, \mathbf{C 5 6}\right)$, 利用 TEM、XRD 对材料进行结构表征, 详细研究了该催化剂 在对硝基苯酚还原过程中的光催化性能和电催化性能. 结果表明, 与未负载壳聚糖的 $\mathrm{Cu}_{2} \mathrm{O}$ 相比, 壳聚糖改性 氧化亚铜 C56 具有更好的光催化性能, 还原速率提高了 1.7 倍, 经过 $\mathrm{CS} @ \mathrm{Cu}_{2} \mathrm{O}$ 修饰的电极表现出更强的电催化 性能，具有较高的还原峰电位以及峰值电流. 该工作基 于以上实验结果，提出了 C56 的催化机理(Scheme 36). 一方面，催化剂活性面(111)晶面的存在增加了局部反 应物中羟基和硝基的浓度; 另一方面，改性后的壳聚糖 带隙能降低, 促使 $\mathrm{CS} @ \mathrm{Cu}_{2} \mathrm{O}$ 纳米颗粒具有更高的催化 活性. 因此, 经过壳聚糖改性后的催化剂 $\mathrm{CS} @ \mathrm{Cu}_{2} \mathrm{O}$ 在 对硝基酚作用过程中具有更高的催化活性. 截至目前, 壳聚糖铜催化剂在氧化还原反应中的应用较少，仅局限 在烯烃氧化以及硫醚氧化. 在后期研究中，通过将壳聚 糖改性，拓展催化剂的种类，应用于更多类型的底物仍 有待进一步发展.
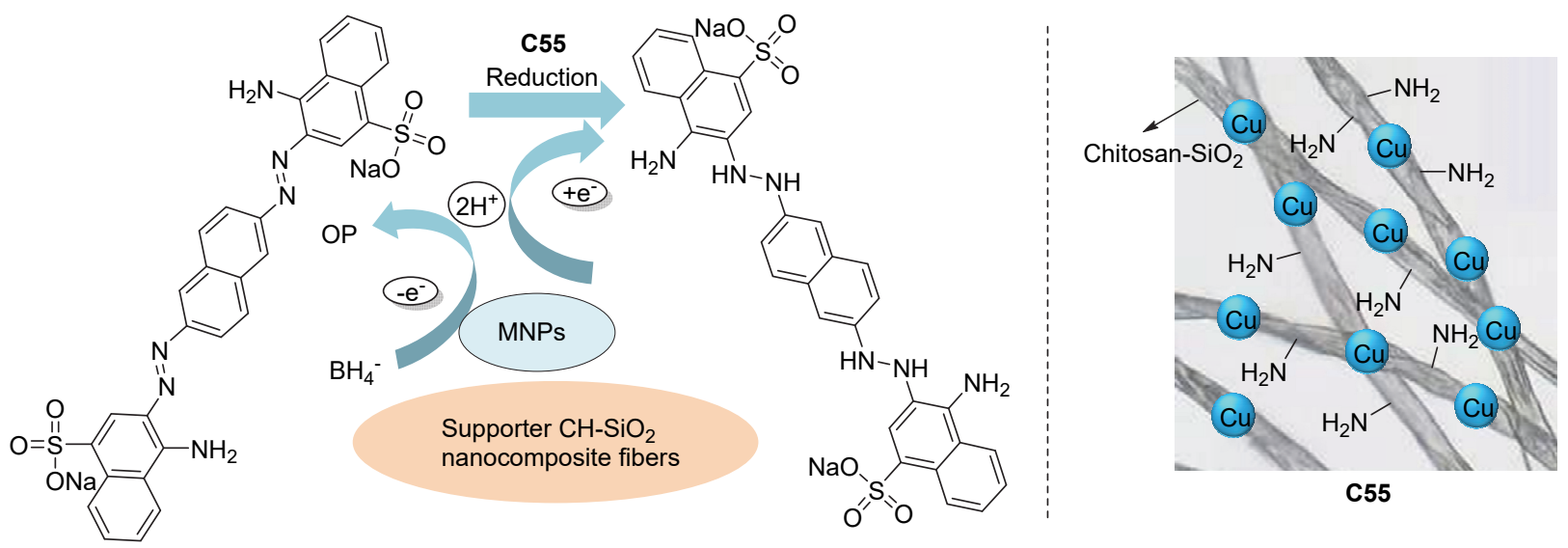

图式 35 在催化剂 $\mathbf{C 5 5}$ 存在下 $\mathrm{NaBH}_{4}$ 还原硝基苯酚的可能机理

Scheme 35 Proposed mechanism for the reduction of nitrophenol by $\mathrm{NaBH}_{4}$ in the presence of $\mathbf{C 5 5}$ 


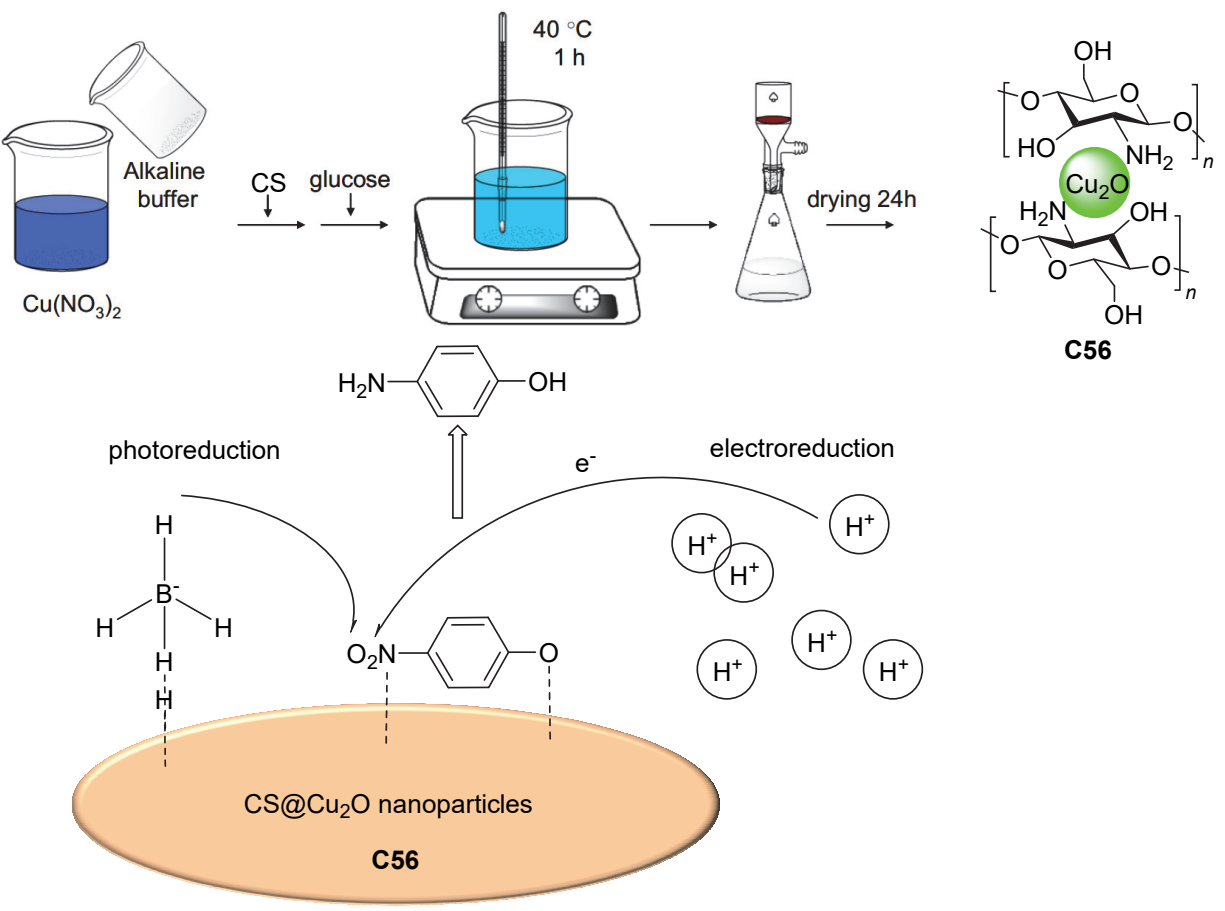

图式 $36 \mathrm{CS} @ \mathrm{Cu}_{2} \mathrm{O}$ 纳米粒子存在下对硝基苯酚的光还原和电还原实例

Scheme 36 Illustration of photoreduction and electroreduction of $p$-nitrophenol reduction with the present of $\mathrm{CS} @ \mathrm{Cu}_{2} \mathrm{O}$ nanoparticles

\section{5 总结与展望}

综上所述，壳聚糖负载铜催化剂的制备是基于壳聚 糖优异的鳌合能力，以壳聚糖或修饰改性后的壳聚糖衍 生物为载体, 负载不同种类的活性铜组分而得. 壳聚糖 的修饰主要是将各种醛类化合物与壳聚糖上的氨基进 行缩合反应，或者先以磁性纳米粒子、硅烷偶联剂等与 壳聚糖反应，制备出含 Schiff 碱结构修饰壳聚糖配体， 再与铜盐络合制备得到催化剂. 修饰后的壳聚糖结构多 样, 均具有良好的载体性能, 易与金属铜盐络合. 无论 是直接以壳聚糖为载体还是修饰改性后的壳聚糖为载 体，在负载铜盐制备催化剂的过程中均具有制备方法简 单、可操作性强等优点. 另外, 不同的金属铜盐与壳聚 糖络合后, 由于铜盐中阴离子对反应影响较大, 所得到 的催化剂性能差异也较大. 在对壳聚糖负载铜后所形成 的催化剂结构、形貌进行表征后, 将其应用于 $\mathrm{C}-\mathrm{C}$ 、 $\mathrm{C}-\mathrm{N} 、 \mathrm{C}-\mathrm{O} 、 \mathrm{C}-\mathrm{S} 、 \mathrm{C}-\mathrm{B} 、 \mathrm{C}-\mathrm{Si}$ 键的构建, 点击化 学反应、氧化还原反应等, 具有应用范围广泛、反应条 件温和、催化剂可回收利用、可生物降解、绿色环保等 诸多优点.

尽管如此，该领域还存在很多挑战，如壳聚糖负载 铜催化剂应用于有机反应的类型仍有待继续拓展, 各种 不同结构催化剂作用时的构效关系仍有待进一步研究. 同时，该类生物质基催化剂在绿色化工领域的应用和实 际生产中新技术的开发方面函待进一步研究, 例如, 将
该类高效的新型生物质基催化剂与微反应连续流动相 技术相结合, 开发出安全高效的生产工艺等, 以提升此 类催化剂的实际应用价值.

\section{References}

[1] Anamika, R. P.; Upasana, S. S.; Munira, M.; Chintan, B. J. Polym. Res. 2017, 24, 1.

[2] Munawar, A. M.; Jaweria, T. M. S.; Kishor, M. W.; Ellen, K. W. Pharmaceutics 2017, 9, 53 .

[3] Mohammed, A. LWT-Food Sci. Technol. 2010, 43, 837.

[4] Prashanth, K. V. H.; Tharanathan, R. N. Trends Food Sci. Technol. 2007, 18, 117.

[5] Choi, C.; Nam, J. P.; Nah, J. W. J. Ind. Eng. Chem. 2016, 33, 1.

[6] Alicia, A.; Naimah, Z.; Ezeddine, H.; Brahim, H.; Fabien, B.; Damien, O.; Francois, C.; Florence, F.; Olivier, H. Molecules 2019, 24 , 3009.

[7] Wang, W.; Meng, Q.; Li, Q.; Liu, J.; Zhou, M.; Jin, Z.; Zhao, K. Int. J. Mol. Sci. 2020, 21, 487.

[8] Pakdel, P. M.; Peighambardoust, S. J. Carbohydr. Polym. 2018 $201,264$.

[9] Kumar, M. N. V. R.; Muzzarelli, R. A. A.; Muzzarelli, C.; Sashiwa, H.; Domb, A. J. Chem. Rev. 2004, 104, 6017.

[10] Mourya, V. K.; Inamdar, N. N. React. Funct. Polym. 2008, 68, 1013.

[11] Jayakumar, R.; Prabaharan, M.; Reis, R. L.; Mano, J. F. Carbohydr. Polym. 2005, 62, 142.

[12] Guo, Z.; Xing, R.; Liu, S.; Zhong, Z.; Ji, X.; Wang, L.; Li, P. Carbohydr. Res. 2007, 342, 1329.

[13] Shepherd, R.; Reader, S.; Falshaw, A. Glycoconjugate J. 1997, 14, 535.

[14] Ren, L.; Yan, X.; Zhou, J.; Tong, J.; Su, X. Int. J. Biol. Macromol. $\mathbf{2 0 1 7}, 105,1636$

[15] Huang, H.; Yuan, Q.; Yang, X. Colloids Surf., B 2004, 39, 31

[16] Ahmed, T. A.; Aljaeid, B. M. Drug Des., Dev. Ther. 2016, 10, 483.

[17] Hussein, M. H. M.; El-Hady, M. F.; Sayed, W. M.; Hefni, H. Polym. 
Sci., Ser. A 2012, 54, 113.

[18] Pereira, F. S.; Lanfredi, S.; González, E. R. P.; Agostini, D. L. D. S.; Gomes, H. M.; Medeiros, R. S. J. Therm. Anal. Calorim. 2017, 129, 291.

[19] Hardy, J. J. E.; Hubert, S.; Macquarrie, D. J.; Wilson, A. J. Green Chem. 2004, 6, 53.

[20] Sahu, P. K.; Sahu, P. K.; Gupta, S. K.; Agarwal, D. D. Ind. Eng. Chem. Res. 2014, 53, 2085.

[21] Baig, R. B. N.; Varma, R. S. Green Chem. 2013, 15, 1839.

[22] Molnár Á. Coord. Chem. Rev. 2019, 388, 126.

[23] Sakthivel, B.; Dhakshinamoorthy, A. J. Colloid Interface Sci. 2017, 485,75 .

[24] Veisi, H.; Ozturk, T.; Karmakar, B.; Tamoradi, T.; Hemmati, S. Carbohydr. Polym. 2020, 235, 115966.

[25] Wang, S.; Zhou, H.; Song, S.; Wang, J. Chin. J. Org. Chem. 2015, 35, 85 (in Chinese) (王硕，周宏勇，宋沙沙，王家喜，有机化学, 2015, 35, 85.)

[26] Tian, T.; Li, Z.; Li, C. Green Chem. 2021, 23, 6789.

[27] Ding, L.; Li, J.; Jiang, R.; Wang, L.; Song, W.; Zhu, L. Chin. J. Polym. Sci. 2019, 37, 1130.

[28] Sun, W.; Xia, C. G.; Wang, H. New J. Chem. 2002, 26, 755

[29] Zeng, M.; Sun, X.; Qi, C.; Zhang X. Kinet. Catal. 2013, 54, 716.

[30] Zhao, H.; Xu, J.; Wang, T. Appl. Catal., A 2015, 502, 188.

[31] Shen, C.; Xu, J.; Ying, B.; Zhang P. ChemCatChem 2016, 8, 3560.

[32] Zhu, L.; Wang, L.; Li, B.; Fu, B. Q.; Zhang, C. P.; Li, W. Chem. Commun. 2016, 52, 6371 .

[33] Shen, J.; Xu, J.; Huang, L.; Zhu, Q.; Zhang, P. Adv. Synth. Catal. 2020, 362, 230

[34] Yuan, J.; Liu, S.; Qu, L. Adv. Synth. Catal. 2017, 359, 4197.

[35] Ramesh, B.; Reddy, C. R.; Kumar, G. R. Reddy, B. V. S. Tetrahedron Lett. 2018, 59, 628.

[36] Dekamin, M. G.; Kazemi, E.; Karimi, Z.; Mohammadalipoor, M.; Naimi-Jamal, M. R. Int. J. Biol. Macromol. 2016, 93, 767.

[37] Anuradha; Layek, S.; Agrahari, B.; Pathak, D. D. ChemistrySelect 2017, 2, 6865 .

[38] Goncalves, F. J.; Kamal, F.; Gaucher, A.; Gil, R.; Bourdreux, F.; Martineau-Corcos, C.; Gurgel, L. V. A.; Gil, L. F.; Prim, D. Carbohydr. Polym. 2018, 181, 1206.

[39] Kaur, P.; Kumar, B.; Kumar, V.; Kumar, R. Tetrahedron Lett. 2018, 59, 1986.

[40] Liu, Q.; Xu, M.; Zhao, J.; Yang, Z.; Qi, C.; Zeng, M.; Xia, R.; Cao, X.; Wang, B. Int. J. Biol. Macromol. 2018, 113, 1308.

[41] Lo, J. C., Kim, D.; Pan, C.; Edwards, J. T.; Yabe, Y.; Gui, J.; Qin, T.; Gutiérrez, S.; Giacoboni, J.; Smith, M. W.; Holland, P. L.; Baran, P. S. J. Am. Chem. Soc. 2017, 139, 2484.

[42] Bodhak, C.; Kundu, A.; Pramanik, A. Tetrahedron Lett. 2015, 56, 419.

[43] Anuradha; Kumari, S; Pathak, D. D. Tetrahedron Lett. 2015, 56, 4135.

[44] Yang, B.; Mao, Z.; Zhu, X.; Wan, Y. Catal. Commun. 2015, 60, 92.

[45] Liu, X.; Chang, S.; Chen, X.; Ge, X.; Qian, C. New J. Chem. 2018, 42, 16013.

[46] Narjes, M.; Nasrollahzadeh, M.; Asghar, T.-K.; Rajender, S. V.; Mohammadreza, S. Carbohydr. Polym. 2020, 232, 115819.

[47] Nasrollahzadeh, M.; Motahharifar, N.; Nezafat, Z.; Shokouhimehr, M. J. Mol. Liq. 2021, 341, 117398.

[48] Shen, C.; Xu, J.; Yu, W.; Zhang, P. Green Chem. 2014, 16, 3007.

[49] Frindy, S.; Kadib, A.; Lahcini, M.; Primo, A.; García, H. ChemCatChem 2015, 7, 3307.

[50] Hajipour, A. R.; Hosseini, S. M.; Jajarmi, S. New J. Chem. 2017,
$41,7447$.

[51] Cheng, L.; Ge, X.; Liu, X.; Feng, Y. Chin. J. Org. Chem. 2020, 40, 2008 (in Chinese) (成琳, 葛新, 刘学民, 冯云辉, 有机化学, 2020, 40, 2008.)

[52] Ying, B.; Xu, J.; Zhu, X.; Shen, C.; Zhang, P. ChemCatChem 2016, 8,1 .

[53] Li, B.; Wang, L.; Qin, C.; Zhu, L. Catal. Commun. 2016, 86, 23.

[54] Wen, W.; Han, B.; Yan, F.; Ding, L.; Li, B.; Wang, L.; Zhu, L. Nanomaterials 2018, 8, 326.

[55] Zhou, L.; Han, B.; Zhang, Y.; Li, B.; Wang, L.; Wang, J.; Wang, X.; Zhu, L. Catal. Lett. 2021, 151, 3220.

[56] Zhu, L.; Li, B.; Wang, S.; Wang, W.; Wang, L.; Ding, L.; Qin, C. Polymers 2018, 10, 385.

[57] Kolb, H. C.; Finn, M. G.; Sharpless, K. B. Angew. Chem., Int. Ed. 2001, 113, 2056

[58] Hennessy, E. T.; Betley, T. A. Science 2013, 340, 591.

[59] Wu, P.; Feldman, A. K.; Nugent, A. K.; Hawker, C. J.; Scheel, A.; Voit, B.; Pyun, J.; Fréchet, J. M. J.; Sharpless, K. B.; Fokin, V. V. Angew. Chem., Int. Ed. 2004, 116, 4018.

[60] Shen, J.; Xu, J.; He, L.; Ouyang, Y.; Huang, L.; Li, W.; Zhu, Q.; Zhang, P. Org. Lett. 2021, 23, 1204.

[61] Shen, J.; Xu, J.; Zhu, Q.; Zhang, P. Org. Biomol. Chem. 2021, 19, 3119.

[62] Chen, L.; Zhang, Y.; Ding, G.; Ba, M.; Guo, Y.; Zou, Z Molecules 2013, $18,1477$.

[63] Chtchigrovsky, M.; Primo, A.; Gonzalez, P.; Molvinger K.; Robitzer, M.; Quignard, F.; Taran, F. Angew. Chem., Int. Ed. 2009, 48, 5916.

[64] Martina, K.; Leonhardt, S. E. S.; Ondruschka, B.; Curini, M.; Binello, A.; Cravotto, G. J. Mol. Catal. A: Chem. 2011, 334, 60.

[65] Baig, R. B. N.; Varma, R. S. Green Chem. 2013, 15, 1839

[66] Jiang, Y.; Wang, Y.; Han, Q.; Zhu, R.; Xiong, X. Chin. J. Org. Chem. 2014, 34, 2068 (in Chinese)

(江云兵, 王彦龙, 韩骞, 朱荣俊, 熊兴泉, 有机化学, 2014, 34, 2068.)

[67] Chetia, M.; Ali, A. A.; Bhuyan, D.; Saikia, L.; Sarma D. New J. Chem. 2015, 39, 5902.

[68] Kumar, B. S. P. A.; Reddy, K. H. V.; Karnakar, K.; Satish, G.; Nageswar, Y. V. D. Tetrahedron Lett. 2015, 56, 1968.

[69] Mahdavinia, G. R.; Soleymani, M.; Nikkhoo, M.; Farnia, S. M. F.; Amini M. New J. Chem. 2017, 41, 3821.

[70] Jennah, O.; Beniazza, R.; Lozach, C.; Jardel, D.; Molton, F.; Duboc, C.; Buffeteau, T.; Kadib, A. E.; Lastécouères, D.; Lahcini, M.; Vincent, J.-M. Adv. Synth. Catal. 2018, 360, 4615.

[71] Zhang, Y.; Han, B.; Zhou, L.; Wang, M.; Li, B.; Wang, L.; Zhu, L. Acta Polym. Sin. 2021, 52, 723 (in Chinese). (张瑶瑶, 韩彪, 周丽洁, 王明宇, 李博解, 汪连生, 朱否, 高分 子学报, 2021, 52, 723.)

[72] Antony, R.; David, S. T.; Karuppasamy, K.; Saravanan, K.; Thanikaikarasan, S.; Balakumar, S. J. Surf. Eng. Mater. Adv. Technol. 2012, 2, 284.

[73] Fakhri, A.; Naghipour, A. Mater. Technol. 2016, 31, 846.

[74] Fakhri, A; Naghipour, A. Environ. Prog. Sustainable Energy 2018, $37,1626$.

[75] Souza, J. F.; Silva, G. T.; Fajardo, A. R. Carbohydr. Polym. 2017, $161,187$.

[76] Ali, F.; Khan, S. B.; Kamal, T.; Alamry, K. A.; Bakhsh, E. M.; Asiri, A. M.; Sobahi, T. R. A. Carbohydr. Polym. 2018, 192, 217.

[77] Guo, Y.; Dai, M.; Zhu, Z.; Chen, Y.; He, H.; Qin, T. Appl. Surf. Sci. 2019, 480, 601 . 